\title{
ريادة الأعمال المهنية المحاسبية في مصر بين الواقع والمأمول: دليل ميداني من مكاتب المحاسبة المصرية
}

\author{
أ.د. عبد الوهاب نصر على \\ أستاذ المحاسبة والمراجعة بكلية التجارة - جامعة الإسكندرية علم الهية
}

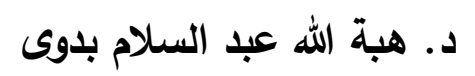

أستاذ المحاسبة والمراجعة المساعد بكلية التجارة - جامعة الإسكندرية والجامعة المصرية اليابانية للعلوم والتكنولوجيا 


\section{ريادة الأعمال المهنية المحاسبية فى مصر بين الواقع والمأمول: دليل ميداني من مكاتب المحاسبة المصرية \\ أ.د. عبد الوهاب نصر على مابل}

أستاذ المحاسبة وإلمراجعة بكلية التجارة - جامعة الإسكندرية علبة

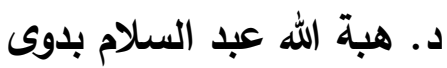

أستاذ المحاسبة والمراجعة المساعد بكلية التجارة - جامعة الإسكندرية والجامعة المصرية اليابانية للعلوم والتكنولوجيا

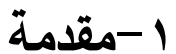

نشهر يومياً مولد، وأيضاً نهاية، العديد من الشركات، المنتجات، الأعمال والخدمات. ويظل الهدف من تعلم ريادة الأعمال Business Entrepreneurship هو السعى بصفة منتظمة نحو اكتثاف أعمال

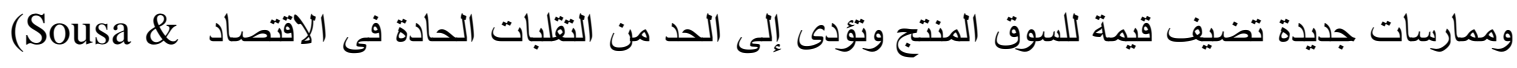
(Almeida, 2014) وتعتبر ريادة الأعمال مكونا أساسيا للتطور والنمو الاقتصادى، فخلق وحدات العات أعمال جديدة لا يؤدى إلى انتاج قيمة مضافة وتحقيق إيرادات وخلق فرص للتوظيف وتحقيق ابتكار فقط، بل يعتبر

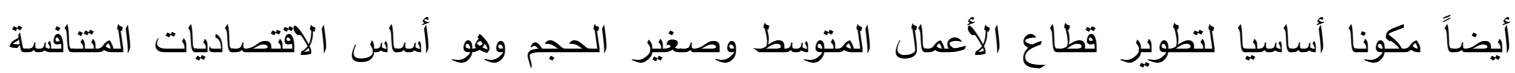
.(United Nations, 2012)

ومن ناحية أخرى، تعتبر المعلومات المحاسبية أهم مدخلات نماذج اتخاذ قرارات المستثرين وغيرهم

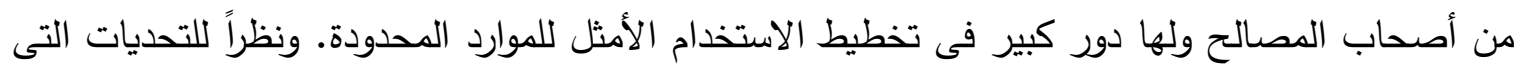

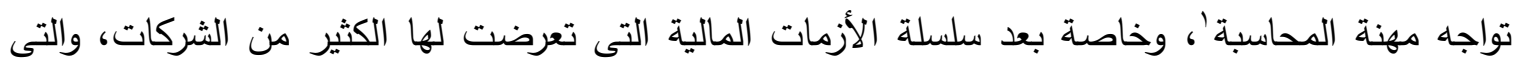

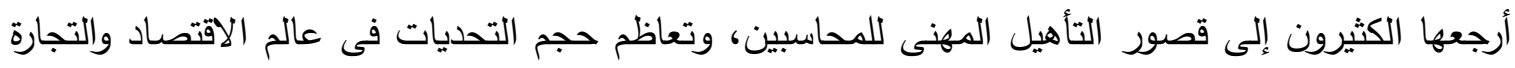

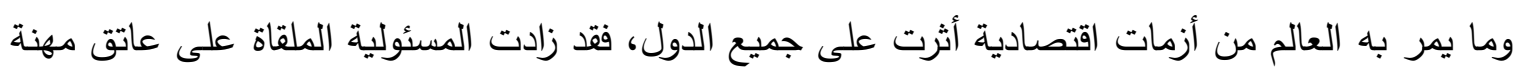

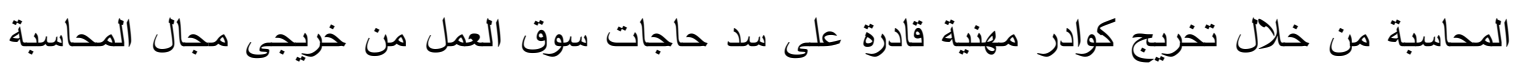

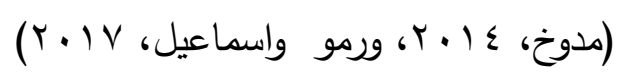

وفى مصر ، زاد الاهتمام بموضوع ريادة الأعمال فى السنوات الأخيرة بعد ارتفاع معدل البطالة بين

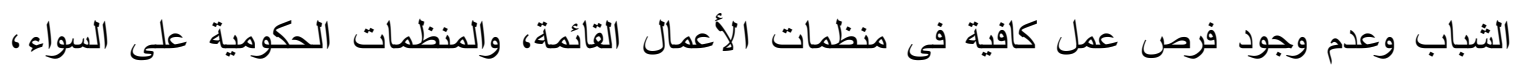

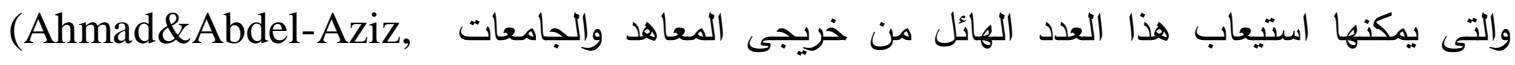

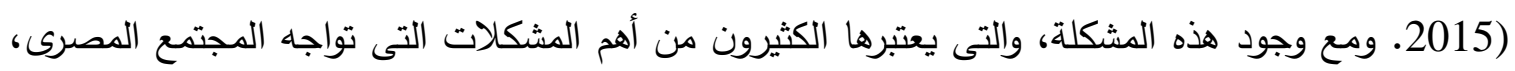
بدأ الإتجاه نحو ريادة الأعمال وزاد عدد رواد الأعمال وخريجى الجامعات الذين لديهم استعداد ولذلك قاموا

' نحن نستخدم مصطلح مهنة المحاسبة Accounting Profession اتساقاً مع الاتحاد الدولى للمحاسبية IFAC 
بالفعل بإطلاق أعمالهم الخاصة بهم.وإذا كان موضوع ريادة الأعمال بصفة عامة من الموضوعات الحيوية

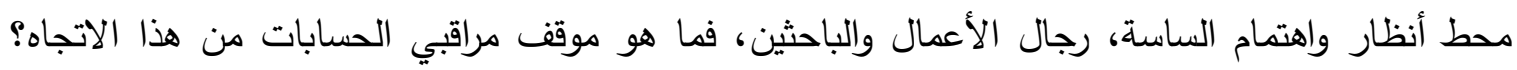

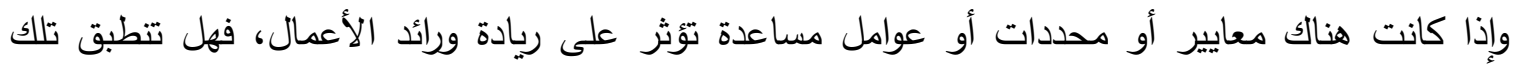

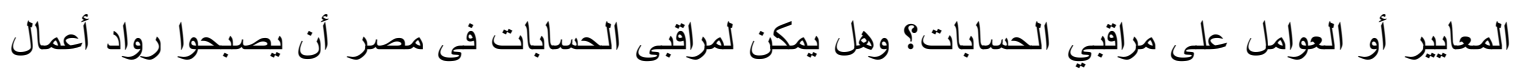
مهنيين؟. هذا ما يسعى البحث للإجابة عليه نظرياً وميدانياً.

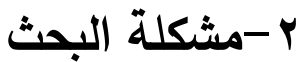

زاد الاهتمام فى الآونة الأخيرة بموضوع ريادة الأعمال وذلك من قبل الساسة ورجال الأعمال والأكاديميين(Marcotte, 2013;Ahmad, \& Abdel-Aziz, 2015;Desai, S., 2017) نظراً لأهمية الشركات، كوحدات اقتصادية، ومساهمتها وحصتها فى الناتج القومى واتجاه الكثير من الثباب وخريجى الجامعات إلى انثاء شركات متوسطة أو صغيرة الحجم. وإذا كان ذلك هو بمثابة إتجاه عالمى ومحلى، فما

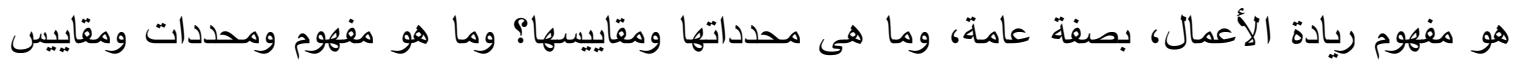

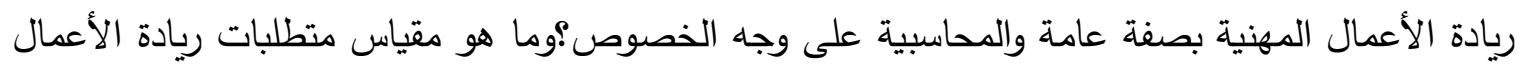
المهنية المحاسبية من وجهة نظر أصحاب المصالح؟ وما هو موقف مهنة المحاسبة وممارسيها فى مصر الهر

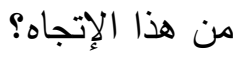

\section{ب- ماف البحث}

يستهدف البحث دراسة والتحقق من مدى قناعة واستيفاء مراقبي الحسابات فى مصر لمتطلبات

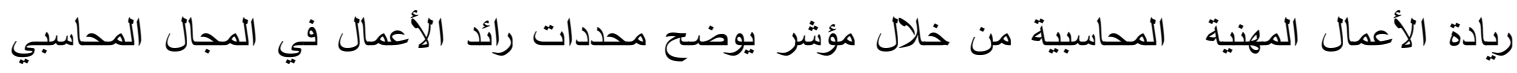
وقياس المستوى الفعلى لاستيفاء مراقب الحسابات في مصر الآن له.

\section{ع -أهمية ودوافع البحث}

أكاديمياً، يأتي هذا البحث ليأخذ المبادرة وليلقى الضوه على إحدى الاتجاهات الحديثة فى مصر

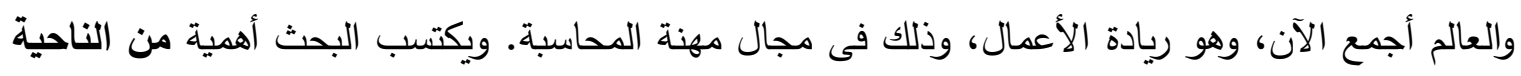
العملية، حيث يصب الاهتمام بموضوع ريادة الأعمال المهنية المحاسبية فى إتجاه خلق فرص عمل جديدة

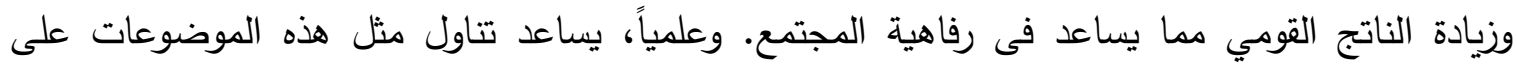
الارتقاء بالبحث العلمي وإلقاء الضوء على موضوعات حديثة يؤثر إيجاباً على جودة التعليم المحاسبي لئي وتعديل المناهج الدراسية بحيث تتتاول مهارات القيادة وريادة الأعمال.

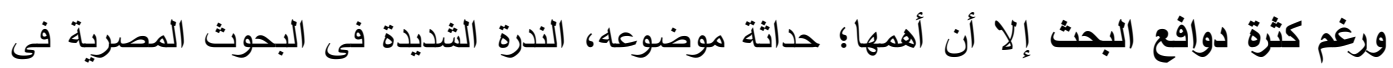

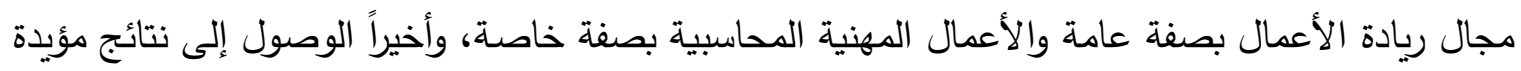
ميدانياً من مكاتب المحاسبة فى مصر ، ويمكن للبحوث المحاسبية التالية البناء عليها. 


\section{ه-حدود البحث}

يقتصر البحث على دراسة واختبار مدى استيفاء مراقبى الحسابات فى مصر لمنطلبات ريادة

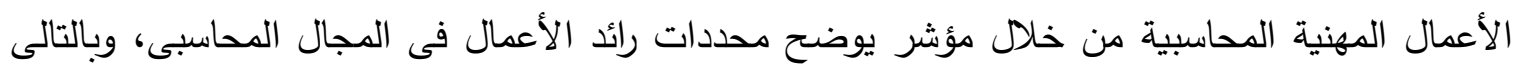

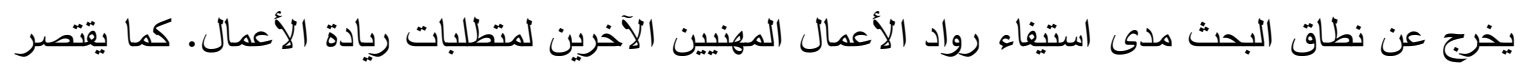

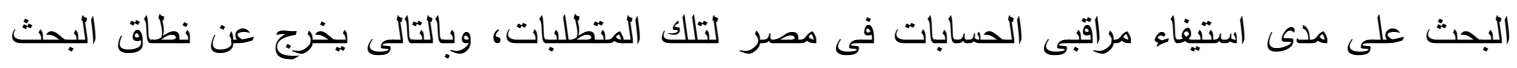

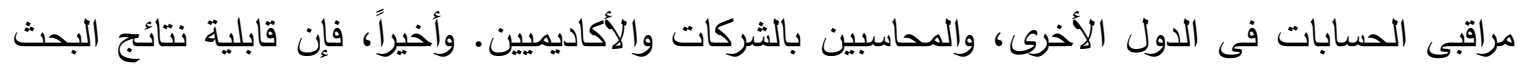
للتعميم مشروطة بضوابط اختيار عينته.

1 -خطة البحث

لتحقيق هدف البحث ومعالجة مشكلته ومن ثم الإجابة على تساؤلاته، فى ضوء حدوده، سوف يتم

استكمال ما تبقى منه كالآتى:

1-1 تحليل الدراسات النظرية فى مجال ريادة الأعمال بصفة عامة والأعمال المهنية المحاسبية بصفة خاصة واشتقاق فرض البحث.

1-1 1-1 مفهوم ريادة الأعمال: المحددات والمقاييس فيس

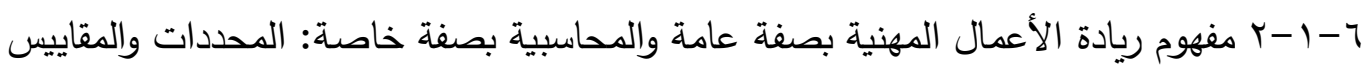

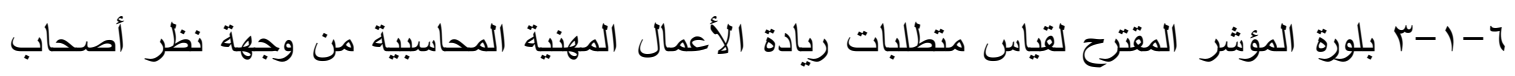
المصالح واشتقاق فرض البحث

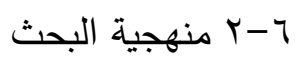

؟-Y-1 أهداف وتوصيف الدراسة الميدانية ب-r-r الإحصاءات الوصفية

r-ץ-r الاختبارات الإحصائية وتحليل نتائج الدراسة الإسة r-r الخلاصة والتوصيات ومجالات البحث المقترحة

צ- 1 تحليل الاراسات النظرية فى مجال ربادة الأعمال بصفة عامة والأعمال المهنية المحاسبية بصفة خاصة واشتقاق فرض البحث

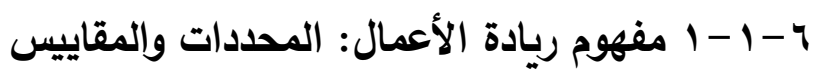

تعددت تعريفات ريادة الأعمال بصفة عامة، فقد عرّهها (Ahmad \& Hoffman, 2007, p. 4)

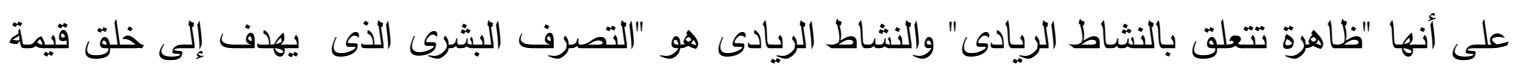

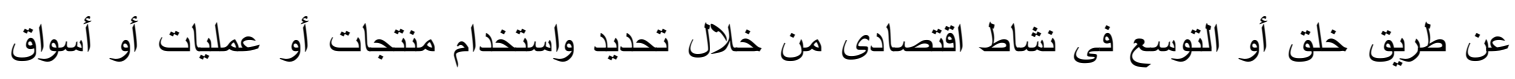

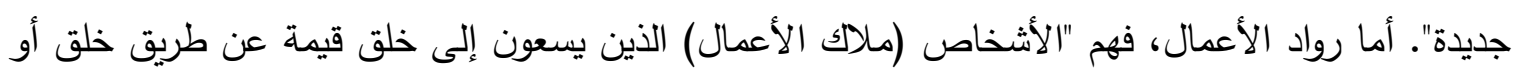

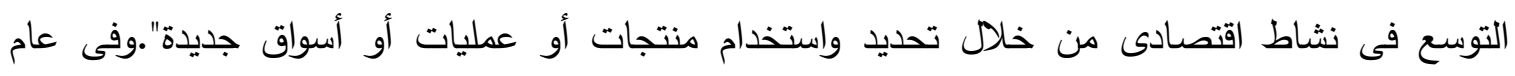




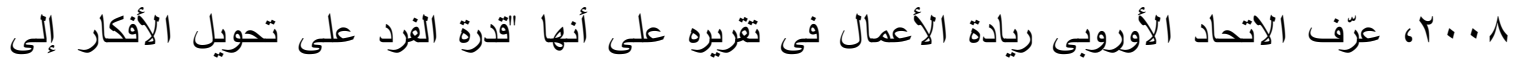
أفعال. ويتضمن ذلك الابتكار والابداع وتحمل المخاطر بالإضافة إلى قدرته على تخطيط وإدارة المشروعات بهدف تحقيق الأهداف. يدعم ذلك كل فرد فى حياته اليومية فى بيته وفى المجتمع ويجعل الموظفين أكثر

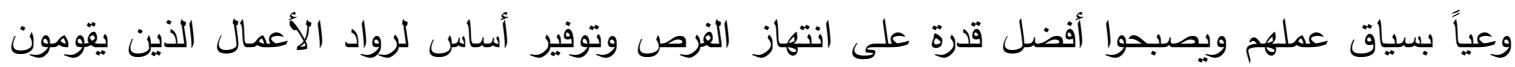
بنشاط تجارى ومجتمعى"(European Commission, 2008, p. 10) وبعد إجراء مقابلات شخصية مع رواد الأعمال وتحديد أنواع رواد الأعمال على أنها: ريادة أعمال اجتماعية social entrepreneurship وريادة أعمال داخل المؤسسة intrapreneuship وريادة أعمال middle market وريادة اعمال سوق وسطى Lifestyle entrepreneurship اسلوب حياه ،highly liquid entrepreneurship وريادة اعمال شديدة السيولة entrepreneurship توصل(Zimmerman(2008, p. 140إلى تعريف لريادة الاعمال على أنها "الاعتراف بـ أو إنثاء فرصة

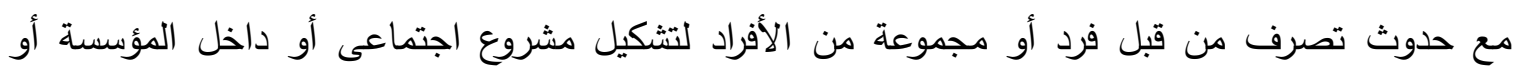
أسلوب حياة أو سوق وسطى أو مشروع شديد السيولة". ومن ناحية أخرى، تناولت دراسة Kobia \& Sikalieh(2010 صعوبة تحديد تعريف واحد وشامل لريادة الأعمال. وعرضت الدراسة لثلاثة مناهج لتعريف ريادة الأعمال. وأشارت الدراسة إلى أن هناك داك دراسات اعتمدت على منهج السمات traits approach لتعريف لريادة الأعمال. ومن خلال هذا المنهج، يتم تعريف رائد الأعمال من خلال سماته وهو حاجته إلى الإنجاز وقدرته على التحكم فى الظروف وأيضاً قدرته

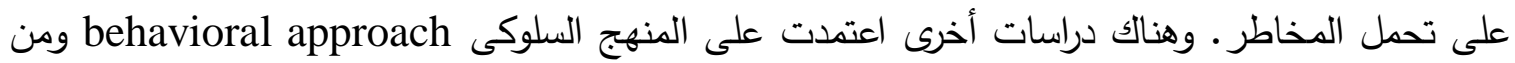

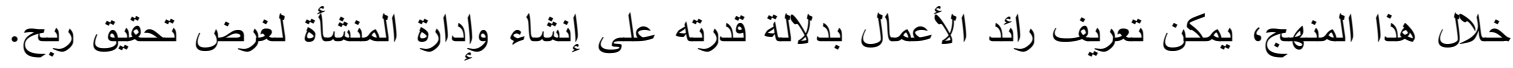
وأخيراً هناك دراسات اعتمدت على منهج تحديد الفرص opportunity identification approach ومن

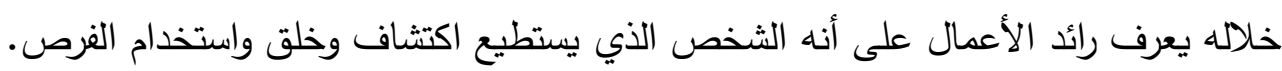
ومن ناحية أخرى، تم تعريف ريادة الأعمال على أنها بمثابة نظام فردى، أو مجمع، وداخلي أو الأ

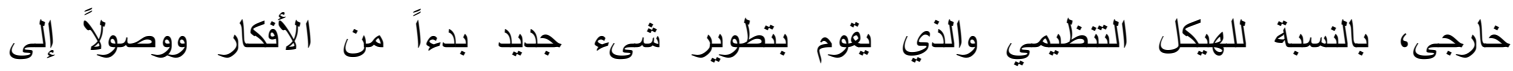
الأعمال) (Sousa \& Almeida, 2014).

ويمكن تبرير عدم الاتفاق على تعريف محدد لريادة الأعمال إلى عدة أسباب وهى: طبيعة ريادة الأعمال التى تعتمد على تخصصات مختلفة multidisciplinary واعتماد كثير من الدراسات ذات الصلة على مداخل نظرية ومنهجيات مختلفة (Law \& Hung, 2009). أما عن أنواع أو أثكال ريادة الأعمال، فتتنوع ما بين ريادة الأعمال الاجتماعية Social

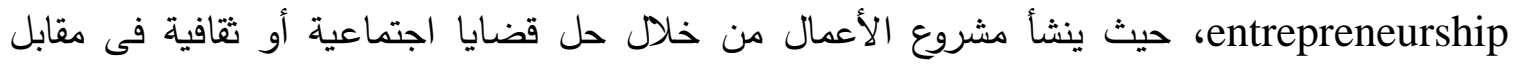

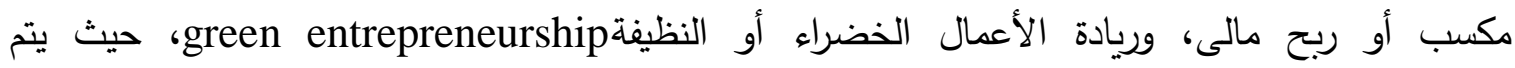
استكثاف مشكلات بيئية مما يؤدى إلى تحقيق تأثير إيجابى على البيئة الطبيعية باستخدام عمليات 
مستدامة، وريادة الأعمال الرقمية digital entrepreneurship، حيث يتم التسويق للمنتجات والخدمات

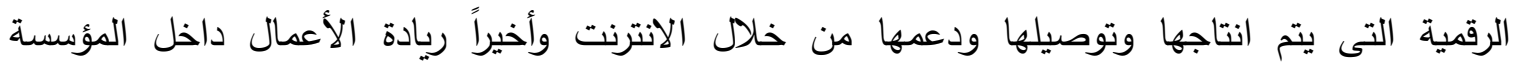

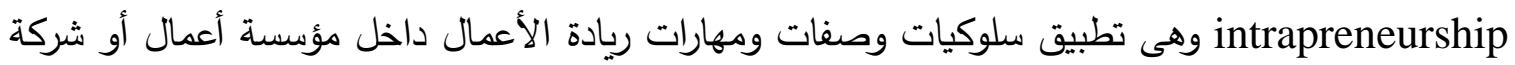
(أو منظمة صغيرة (QAA', 2018) وبما أن رائد الأعمال هو أساس ريادة الأعمال، وبما أن مهاراته تعتبر ركيزة أساسية لانجاح

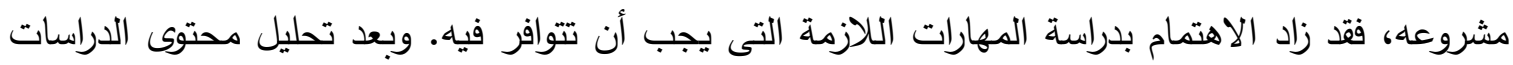

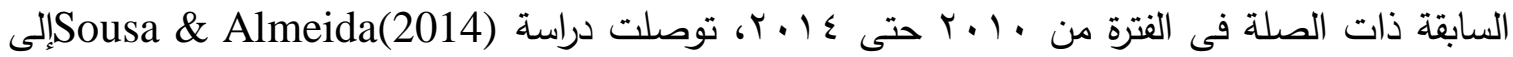
إطار يضم مهارات ريادة الأعمال، حيث تتمثل تلك المهارات فى مجموعتين من المهارات. تثتمل المجموعة

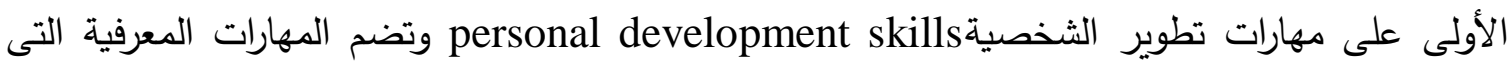
تتعلق بالتفكير الإبداعى، صياغة وحل المشكلة وإتخاذ القرار، والمهارات الفنية التى تدمج مفاهيم الخبرة الفنية، ومهارات الإدارة التى تدمج المعرفة بالخطط المحتمل تطبيقها فى الثركات والقدرة على إتخاذ القرارات business الاستراتيجية. كما تثتمل المجموعة الثانية من مهارات ريادة الأعمال على مهارات الأعمال skills فبالإضافة إلى ذلك، يجب أن يكتسب رائد الأعمال مهارات تتعلق بتطوير الأعمال، والتى تتضمّن الاستراتيجية التى ستقوم الثركة بتطبيقها، المنتجات و/أو الخدمات، النظم الادارية (مثل إدارة الموارد البشرية والتسويق) والهيكل الرسمى وغير الرسمى للثركة.

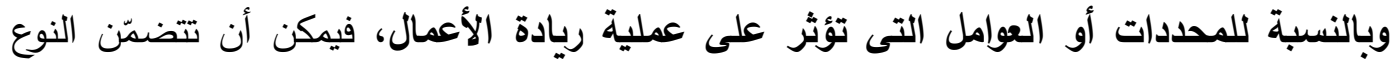
والسن ومدى الاشتراك فى أعمال العائلة)family business(Rayan \& Aryasri, 1999والسياسة العامة للدولة مثل معدلات الضريبة ووجود الجامعات البحثية والتى تعتبر مصدراً محتملاً للتكنولوجيات التى يمكن

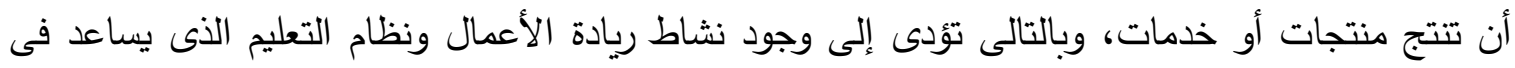

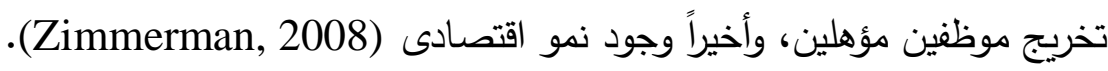
وقد تناولت الدراسات السابقة) Ahmad \& Hoffman, 2007; Lunati, 2010) عملية ريادة الأعمال، وأشارت إلى أن إطار ريادة الأعمال يتضمّن محدداتها والأداء الريادى ومخرجاتها. فيما يتعلق

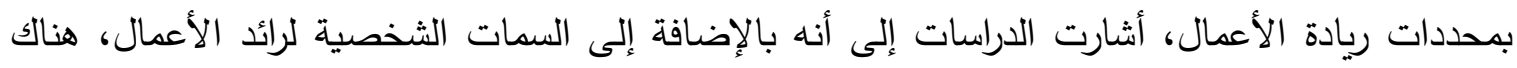

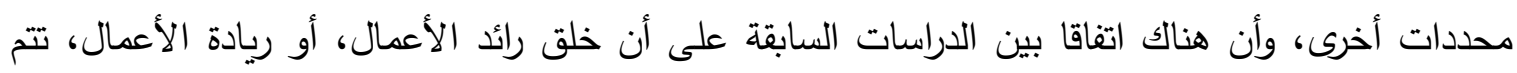
من خلال مزيج من ثلاثة عوامل، وهى الفرص والأفراد ذوى المهارات والإمكانات أو الموارد. وتتأثر هذه العوامل الثلاث بعاملين مهمين وهما الإطار التتظيمى المحيط والثقافة. وتتمثل الموارد والإمكانات فى التى إمكانية الوصول إلى رأس المال والحصول على قروض بنكية، والبحوث والتطوير التى تساعد رائد الأعمال

'وكالة ضمان الجودة للتعليم العالى Quality Assurance Agency for Higher Education (QAA) وهى جهة مستقلة تختص بالتفتيش على ومراجعة معايير وجودة التعليم العالى بالمملكة المتحدة. 
على خلق منتجات أو عمليات جديدة، والتكنولوجيا. أما بالنسبة للأفراد ذوى المهارات، فتتمثل فى رأس المال البشرى والاجتماعى لرواد الأعمال. وبالنسبة للفرص، فهى تلك التى تخلقها الظروف السوقية فى الدولة،

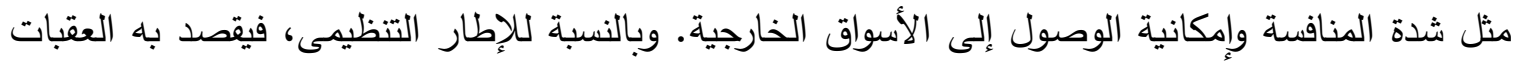
التى تواجه رواد الأعمال وقوانين الضرائب وجميع القوانين العامة والمؤسسات التى تؤثر على رواد الأعمال.

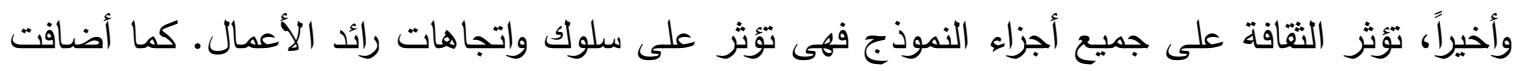

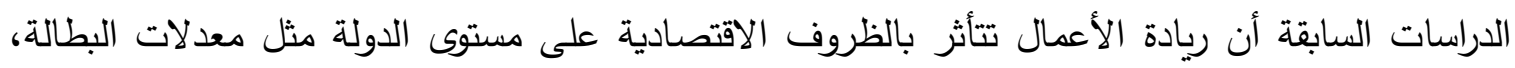

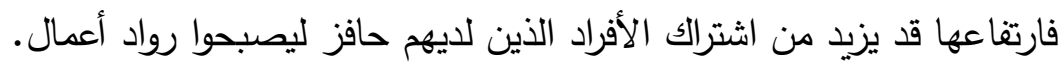
وعلى المستوى الدولى، تتاولت دراسة (Iversen, Jorgensen \& Malchow-Moller, 2008) كيفية قياس ريادة الأعمال. وأشارت إلى أن هناك مقاييس مختلفة، مثل معدل التوظيف الذاتى. وهو برغم

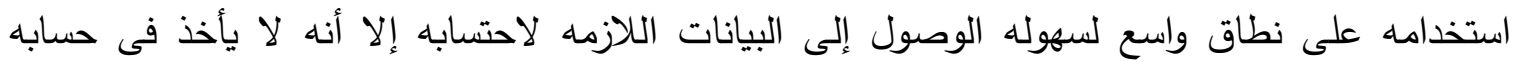

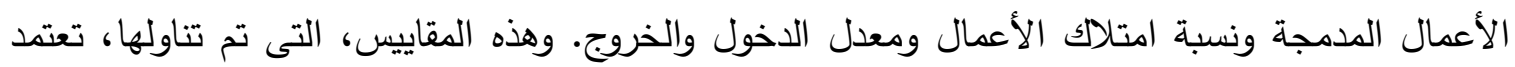

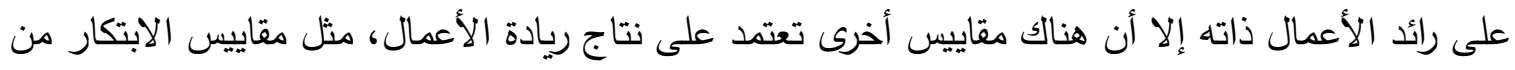

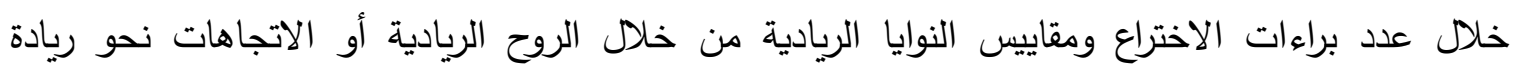

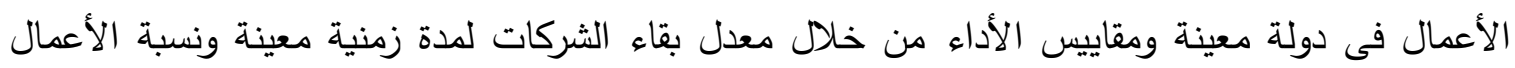
الجديدة إلى إجمالى الأعمال والنصيب النسبى للنشاط الاقتصادى من قبل الثركات الصغيرة. وفى نفس السياق، تتاولت دراسة (2013) Marcotte المؤشرات العالمية لريادة الأعمال، وأشارت

إلى أن أولى هذه المؤشرات هى مؤشر ريادة الأعمال العالمى Global Entrepreneurship Index ويقوم على مجموعة من المؤشرات الأساسية وهى: إجمالى النشاط الريادى ويقاس من خلال ( ) (GEM)

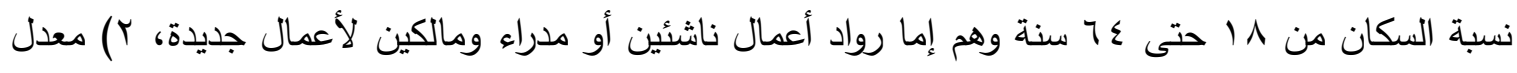

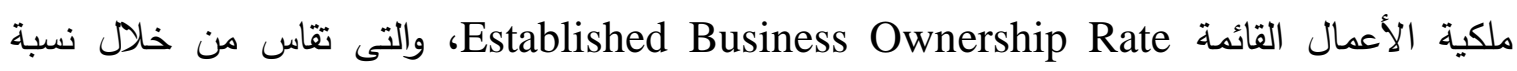

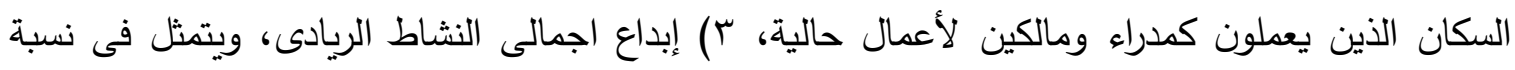

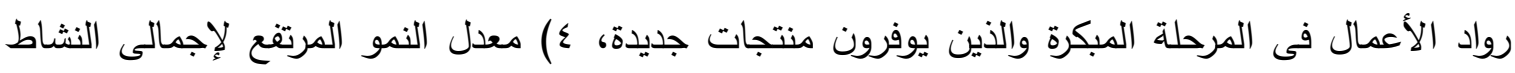

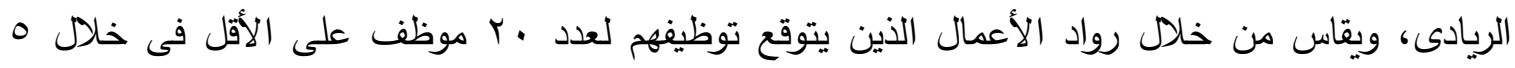

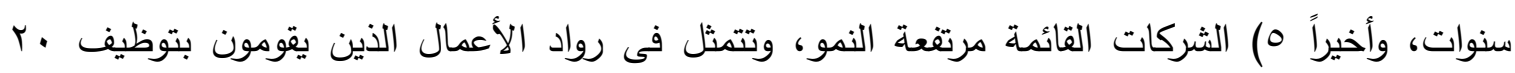
موظف أو أكثر . منوات واخير وتعتبر القيادةleadership أحد المكونات الأساسية لريادة الأعمال. وقد تتاولت الدراسات السابقة

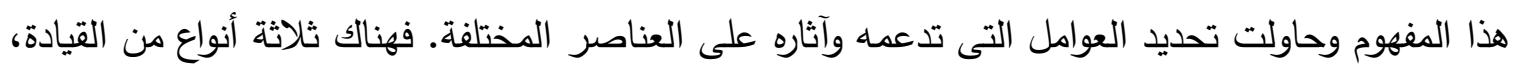
القيادة التحويلية transformational leadership والقيادة التبادلية transactional leadership والقيادة التي تقوم على أساس عدم التدخل Laissez Faire leadership. تقوم القيادة التحويلية على أساس شخصية القائد وقدرته على أن يكون ملهماً للعاملين وتركز على وضع القائد لأهداف الهنظمة وتحفيز 
العاملين على تحقيقها وتثجيعهم على الإبداع. وتقوم القيادة التبادلية على أساس تحديد القائد لأهداف

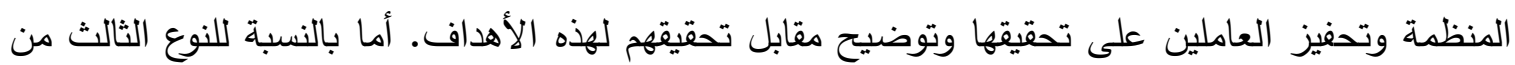
القيادة، والذي يقوم على أساس الحرية وعدم التدخل، فهى تقوم على أساس تخفيض مستوى الاشراف وترك الحرية للعاملين للتصرف (Dal Mas \& Barac, 2018). ونظراً لأهمية موضوع ريادة الأعمال والدور الذي يمكن أن تلعبه الجامعات في هذا الصدد من حيث تعليم طلابها مهارات ريادة الأعمال والقيادة ودمجها فى مناهجها الدراسية، فقد اهتم الكثيرون بالتعليم

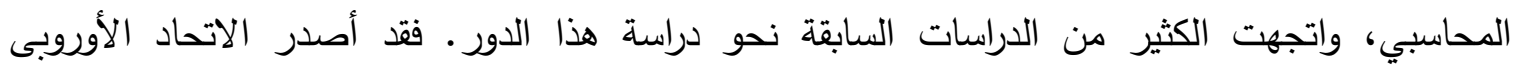
(European Commission, 2008) العوامل التى تساعد فى فعالية تعليم ريادة الأعمال. وتتضمن هذه العوامل تبنى الدولة لسياسة ريادة الأعمال

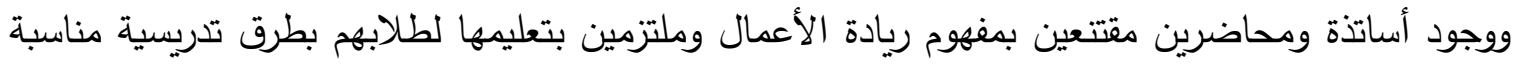

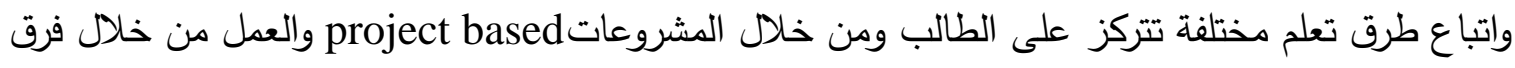

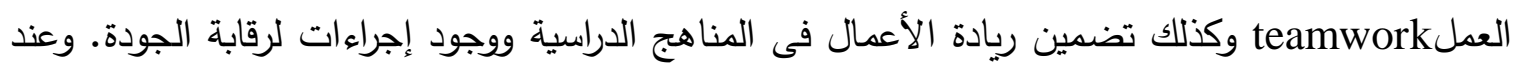

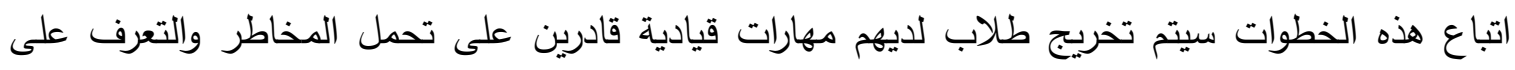
الفرص واتخاذ القرارات وحل المشكلات والعمل مع فرق العمل المختلفة.

ويخلص الباحثان مما سبق إلى أن هناك اهتماما متزايدا من قبل الأكاديميين والباحثين

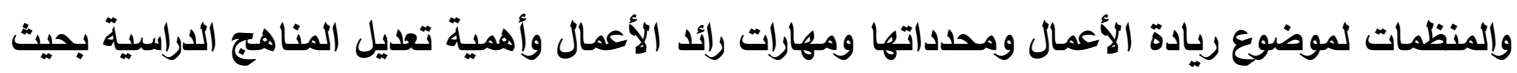

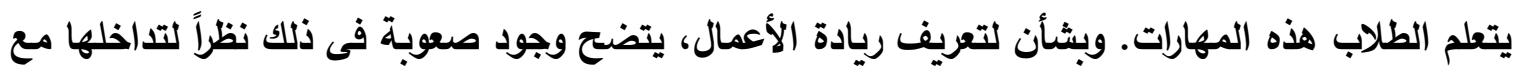
المعارف المختلفة واعتماد كثير من الاراسات السابقة على مداخل نظرية ومنهجيات مختلفة لتناولها.

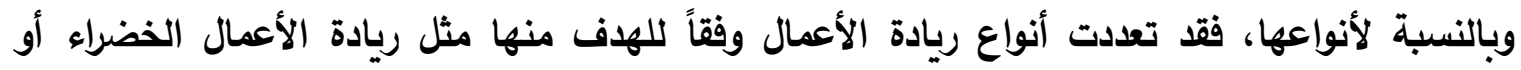

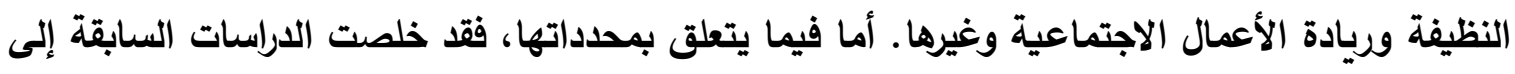
أن هناك عوامل مختلفة، على المستوى الثخصى والمستوى المحلى، والتى يمكن أن تؤثر إيجاباً أو سلباً

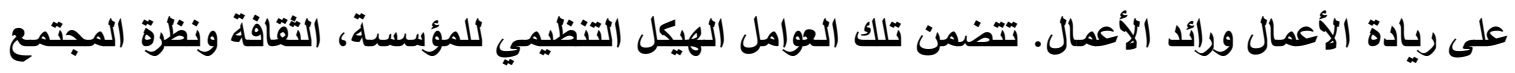

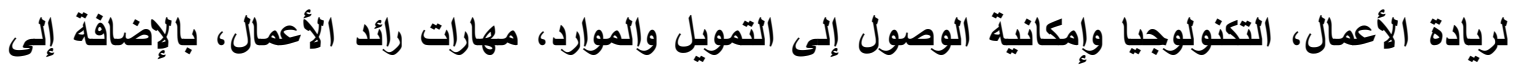

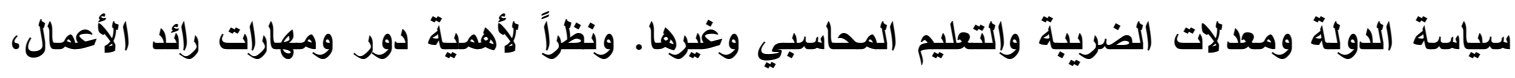

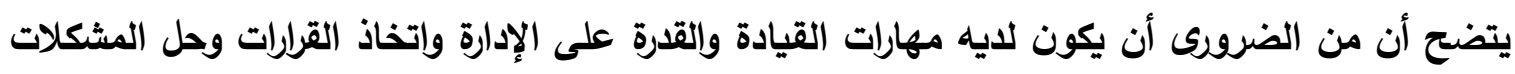
وتحمل المخاطر وغير ذلك. צ-1-1 مفهوم ريادة الأعمال المهنية بصفة عامة والمحاسبية بصفة خاصة: المحددات والمقاييس 
تعتبر المحاسبة "فنا يعتمد على استخدام القدرات الذاتية للمحاسبين فى الحكم على كثير من

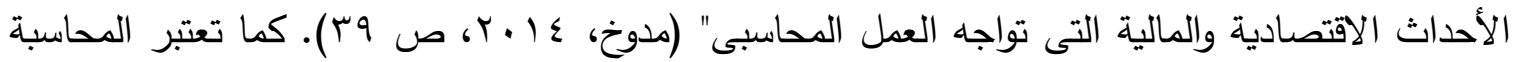
من العلوم الاجتماعية التى يتطلب ممارستها توافر الخبرة والدراسة معاً، كما تعتبر مهنة(Huber, 2012). أيضاً تحتاج ممارسة مهنة المحاسبة ضرورة توافر أسس علمية والقدرة على الحكم على أمور متعددة تتعلق بالعمل المحاسبى. كما تتطلب ممارسة مهنة المحاسبة توافر العديد من المهارات والتى تبدأ من مهارة القياس وصولاً إلى تحليل الأمور واتخاذ القرارات (مدوخ، ع ( ب ب). أيضاً يمكن تحديد مواصفات المحاسب المؤهل فى ثلاثة جوانب: الجانب العلمى، والمتمثل فى المعارف المهنية، والجانب العملى والمتمثل فى المهارات

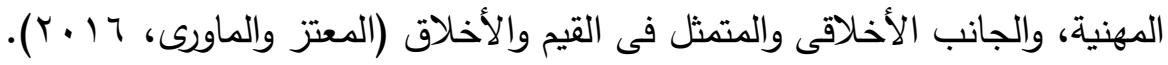
وتتمثل خصائص مهنة المحاسبة فى ما يلى: إتقان مهارة ثقافية معينة والتى يتم الحصول عليها من خلال التدريب والتعليم، قبول المحاسب لواجباته نحو المجتمع ككل بالإضافة إلى واجباته تجاه العميل،

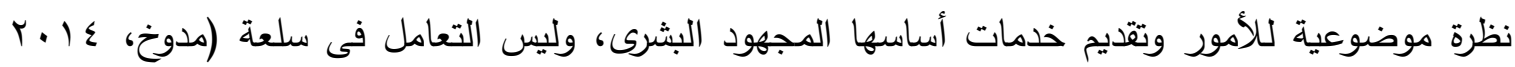
نقلاً عن الخداش وآخرون، ؟ . . ب). وبالطبع لا يمكن تجاهل قواعد الأخلاقيات والسلوكيات المهنية أيضاً.

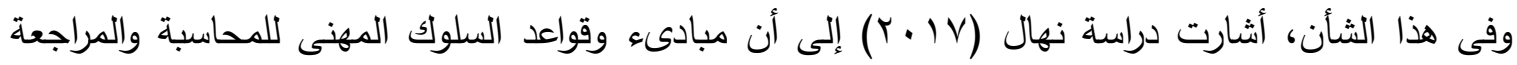
تتمثل فى تتمية روح التعاون والمشاركة بين المحاسبين بصفة عامة ومراقبى الحسابات بصفة خاصة والعمل على رعاية مصالحهم، العمل على كسب ثقة المتمع من خلال توفير معلومات موثوق فيها بحيث يستطيع متخذو القرارات الاعتماد عليها، رفع مستوى مهنة المحاسبة وتدعيم النصوص القانونية والأحكام لتوفير الكفاية المهنية والعملية للمحاسب المهنى والسعى إلى تحقيق مستويات أداء مرتقعة للمحاسب المهنى. وبشأن مفهوم ريادة الأعمال المهنية المحاسبية،فهو مفهوم حديث نسبياً. ويمكن القول أن ريادة الأعمال المهنية المحاسبية هى النشاط الذى يقوم به المحاسبون بهدف إضافة قيمة للمجتمع بصفة عامة ومهنة المحاسبة على وجه الخصوص، وذلك من خلال التركيز على مهارات رائد الأعمال، ولكن بما يتفق مع طبيعة مهنة المحاسبة. وتتضمن تلك المهارات التى يجب توافرها فى رائد الأعمال المهنى المحاسبى المهارات القيادية، تقديم خدمات محاسبية جديدة، ابتكار أدوات محاسبية جديدة، تطوير شبكة من العلاقات مع الزملاء والعملاء وأصحاب المصالح بصفة عامة والاعتماد على تكنولوجيا المعلومات والاتصالات فى أداء عملهم.

Schoch \& و وقد بدأ التعرف على الدور الريادى للمحاسبة منذ القرن الماضى، حيث تتاولت دراسة Teoh (1995) الدور الريادى الذى يمكن أن يقوم به المحاسب فى مجال التكاليف بحيث يستطيع مساعدة العاملين فى مجال التسويق. ومن خلال تحليل الدراسات السابقة التى ركزت على العلاقة بين السعر والتكلفة والربط بين المحاسبة والتسويق، وجدت الدراسة أن للمحاسب مهارات ومعرفة مالية تمكنه من القيام بدوره الريادى، حيث يمكن للمحاسب تحليل المشكلات التى تواجه العاملين فى مجال التسويق مثل تصميم خطط التسعير وأيضاً عند إعداد تحليل ربحية القطاعات السوقية. وأضافت الدراسة أن للمحاسبين قدرة على تطوير 
أدوات تحليل تستخدم فى مجال التسويق، وحتى يتم تطبيق مفاهيم وأدوات جديدة فى محاسبة التكاليف،

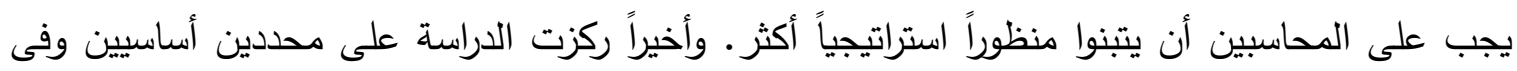
غاية الأهمية بالنسبة للمحاسب الريادى، وهما أن نجاح هذا الدور يتطلب توافر عنصر الابتكار وذلك من خلال مساعدة العاملين فى مجال التسويق فى وضع وقياس تحقيق الأهداف، والتى ستؤدى إلى زيادة ثروة

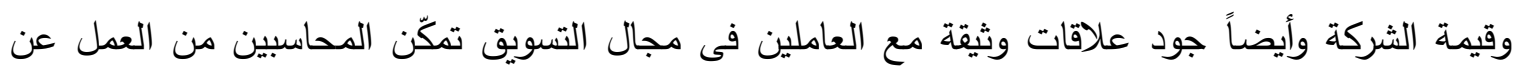
قرب معهم والعمل على حل مشكلاتهم. ومن خلال دراسة حالة على إحدى شركات الاتصالات التابعة للحكومة البريطانية، قامت دراسة بتناول دور المحاسبين كرواد أعمال مؤسسين فى عملية Sharma, Lawrence \& Lowe (2014) تحويل الثركة محل الدراسة من شركة تقوم على البيروقراطية وتدار من خلال الحكومة وتتتشر بها الأعراف والمفاهيم الهندية إلى شركة تدار من خلال الأعمال وتقوم على أساس محاسبى. وقد أوضحت الدراسة

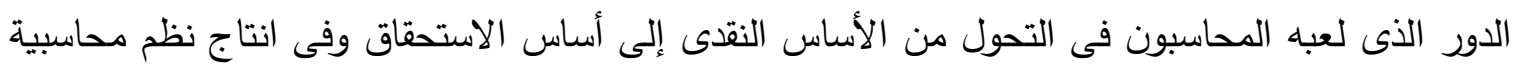

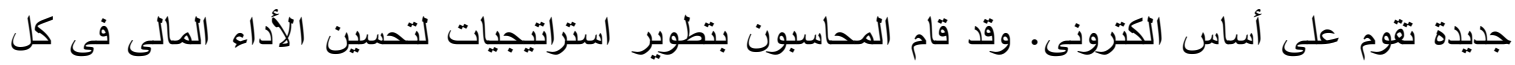

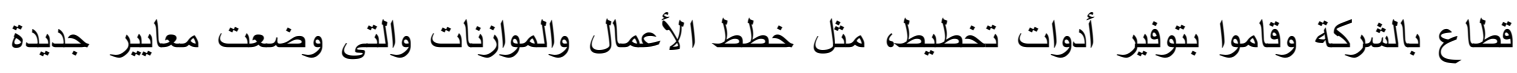

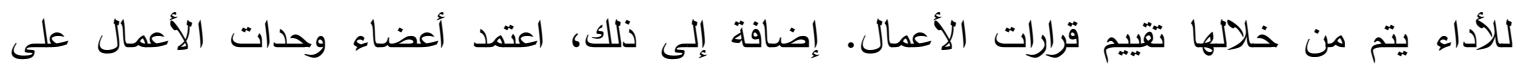

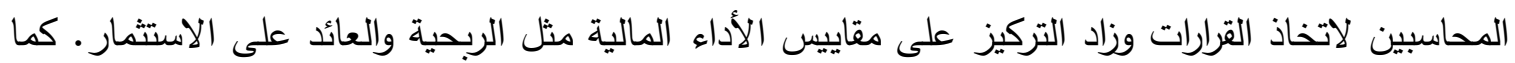
تم تطوير بعض المقاييس غير المالية مثل رضا العملاء وتدريب الموظفين من قبل المحاسبين ورؤساء

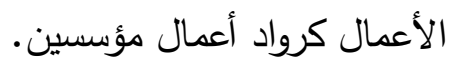
ومن ناحية أخرى، تتاولت دراسة (2016) Murigi خصائص المحاسبين التى مكنتهم من إدارة الأعمال بنجاح. فقد رأت الدراسة أن المحاسبين تم تدريبهم بحيث يمتلكون مهارات مثالية، فالمحاسبون لديهم مهارات مختلفة تتعلق بالاتصال والعمل من خلال الفرق وإدارة الوقت والقدرة على العمل بطريقة منطقية.

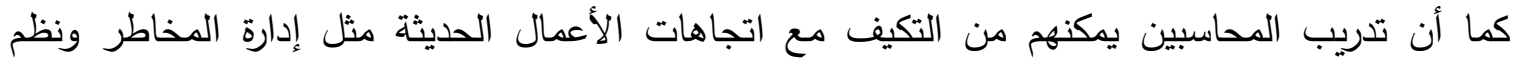
تكنولوجيا المعلومات الجديدة. أيضاً يستطيع المحاسبون فهم آليات الأعمال ويستطيعوا اتخاذ قرارات الأبطات

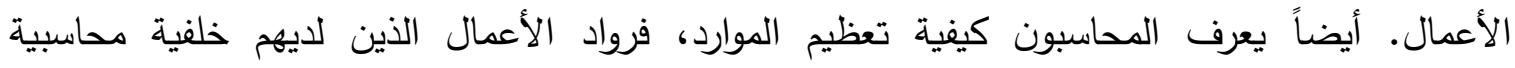
يستطيعون تقييم المخاطر وتخطيط خطة مالية بدقة. وفى نفس السياق، تتاولت دراسة Mitter \& Hiebl (2017 دور الدحاسبة الإدارية فى ريادة

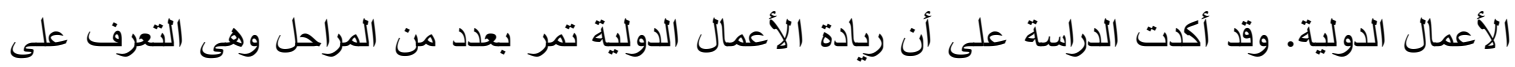
فرص الأعمال وتتفيذها وتقييمها. ومن خلال عدد من دراسات الحالة على عدد من الشركات الاسترالية،

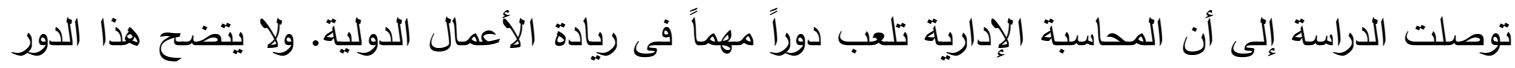
فى مرحلة التعرف على فرص ريادة الأعمال ولكن يظهر وبثكل واضح عند تقييم المخاطر ذات الصلة. 
فكلما كان مستوى المخاطر أعلى كلما زاد دور المحاسبة الإدارية فى هذا الصدد. أيضاً تساعد المحاسبة الإدارية فى تقييم خطوات ريادة الأعمال الدولية وفى تثكيل وتسهيل عملية اتخاذ القرار . وفى مجال المراجعة، تناولت دراسة (2009) Law \& Hung العلاقة بين خمسة عوامل ومدى

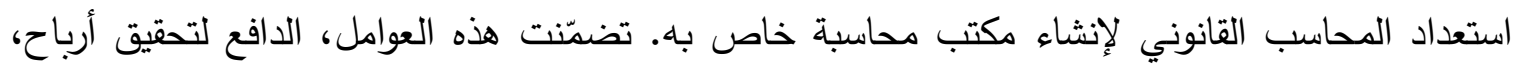

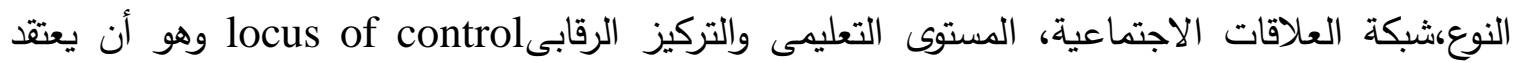

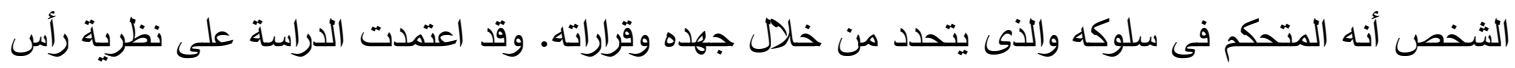

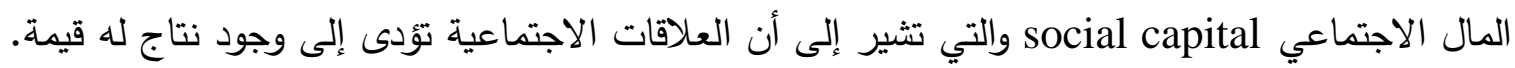
ومن خلال عينة من r T Tحاسب قانوني فى الصين، توصلت الدراسة إلى أن العلاقات الاجتماعية

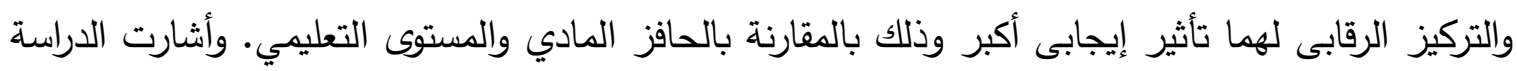

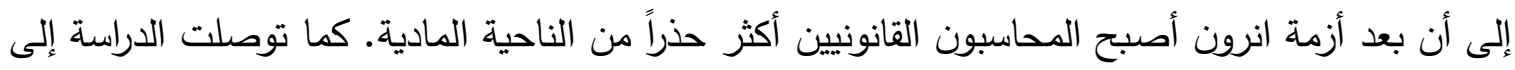

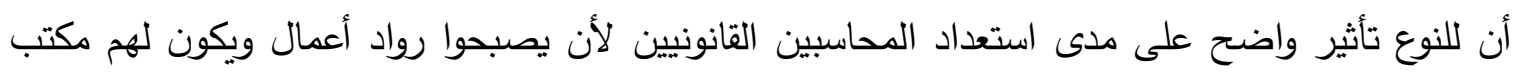
محاسبة خاص بهم حيث تزيد نسبة إنثاء وامتلاك الذكور لـكاتب المحاسبة بالمقارنة بالإناث.

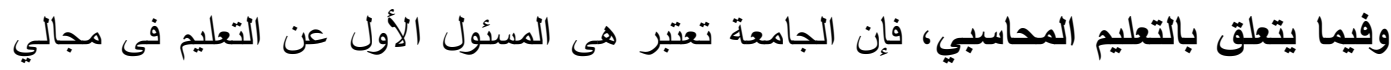
المحاسبة والمراجعة. ولذا يجب عليها تزويد الطلاب بالمعارف والمهارات التى تستلزم توافرها لممارسة المهنة وبما يمكنهم من مواكبة التطور فى المعارف المختلة (المريش، ع.. ب). وقد ركزت كثير من الدراسات السابقة على أهمية تكنولوجيا المعلومات، سواء من خلال استخدامها فى تدريس المناهج الدراسية أو من خلال تعليم الطلاب المهارات التكنولوجية التى تمكنّهم من مواكبة التطور فى هذا الهجال. ويعتبر التعليم

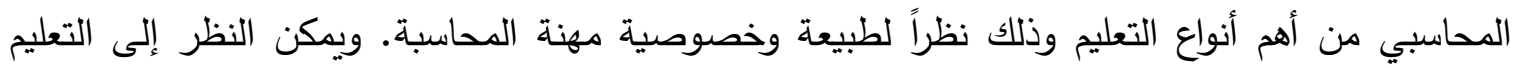

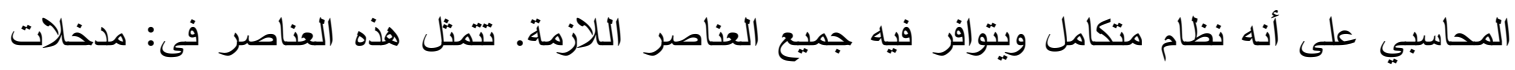
النظام والمتمثلة فى الأشخاص الذين تهيأت لهم فرصة ممارسة العمل المحاسبى، العمليات التشغيلية والمتمثلة فى وسائل التعليم والتي يمكن الاعتماد عليها لتعليم الطلاب المهارات والمعارف المحاسبية، مخرجات النموذج والتى تتمثل فى الأشخاص المؤهلين والذين يمكنهم ممارسة العمل المحاسبى، وأخيراً التغذية العكسية feedback، والتى تتضمّن تقييم عناصر النموذج الثلاثة السابقة وذلك بهدف التطوير بما

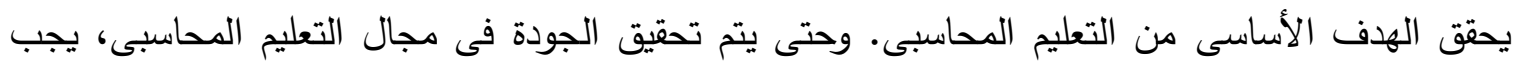

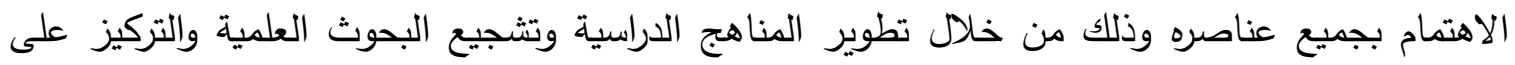

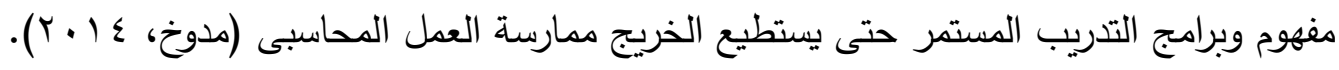

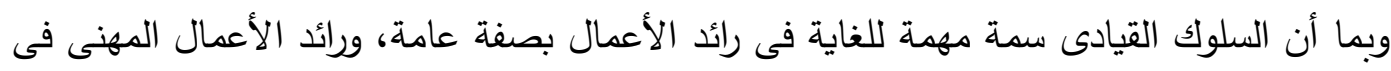

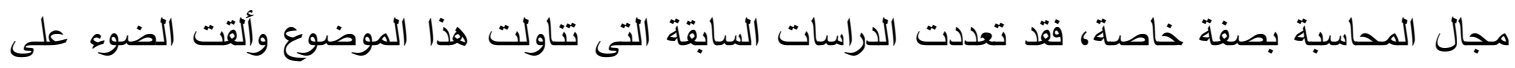

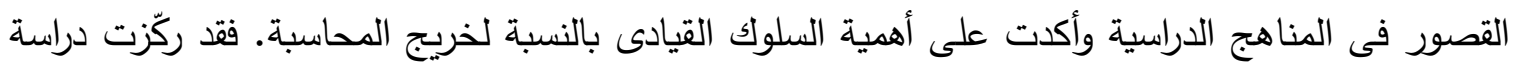
Bloch, Brewer \& Stout(2012) 
وذلك بعد التأكد من وجود قصور فى مناهج المحاسبة وعدم اهتمام القائمين بتدريسها بتضمينها فى المناهج الدراسية. اعتمدت الدراسة على منهج دراسى يتكون من 1 موضوعات تم تصميمه بحيث يتم تدريسه على

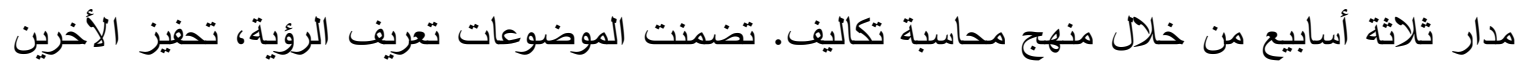
على تنفيذ الرؤية، تحفيذ فرق العمل على تنفيذ الرؤية، خلق حوكمة فعالة، خلق ثقافة أخلاقية واتخاذ قرارات أخلاقية. ومن خلال تقييم المنهج الدراسى من قبل الطلاب المشاركين، اتضح أهميته فى تهيئة الطلاب

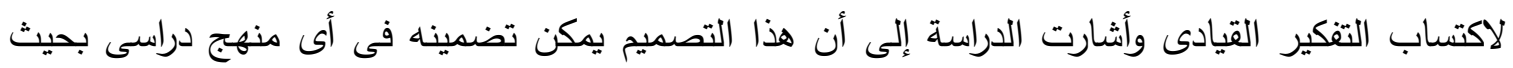

$$
\text { يساعد الطلاب على اكتساب المهارات المناسبة. }
$$

وقد تناولت دراسة Schiopoiu, Mihai \& Mihai(2016) أهمية المناهج الدراسية فى تطوير

Economics and السلوك القيادى لطلبة المحاسبة. وقد اعتمدت الدراسة على ردود 10 بالب بكلية Craiova برومانيا على قائمة استقصاء تتناول العوامل المؤثرة فى سلوكهم القيادى ، مثل مصدر القيادة، الاثتراك فى عملية اتخاذ القرار، صورة مهنة المحاسبة، المناهج الدراسية،القيم الأخلاقية ومهارات القيادة.وأشار الطلاب إلى أنهم لا ينظرون إلى أنفسهم على أنهم تابعين

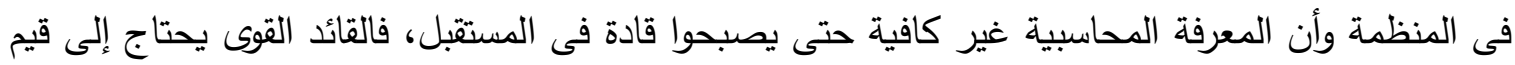
أخلاقية والالتزام بالمعايير الدحاسبية والمالية والأخلاقية. وقد توصلت الدراسة إلى أهمية المعرفة والقيم

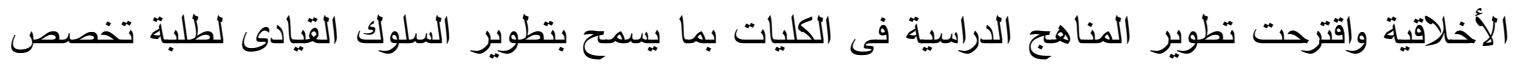

$$
\text { المحاسبة ودمج مهارات القيادة فى جميع المعارف الأخرى. }
$$

وبالنسبة لقيادة المهنة، قامت دراسة(2015) Sellers, Fogarty \& Parker بالتحقق من مدى في قيادة المعهد الأمريكى للمحاسبين القانونيين AICPA لمهنة الدحاسبة من خلال دراسة طولية على الفترة

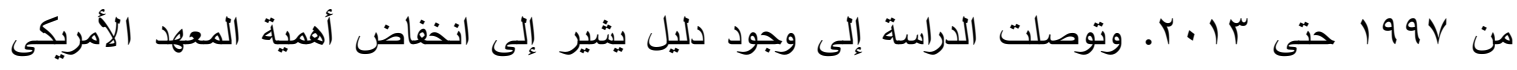

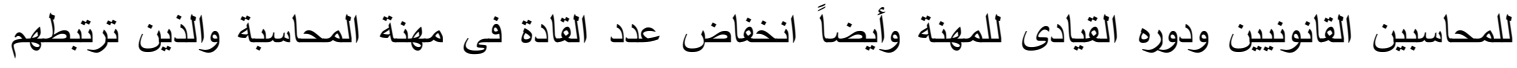
علاقات واضحة بالمعهد الأمريكى للمحاسبين القانونيين. كما توصلت الدراسة إلى أن تدخل مكاتب

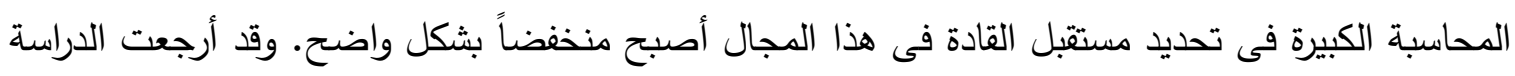
هذه النتائج إلى التغير فى طبيعة المهنة والقصور فى المعهد الأمريكى للمحاسبين القانونيين وممارسة

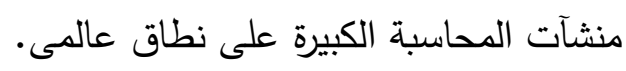

ويتضح مما سبق أن مفهوم ريادة الأعمال المهنية المحاسبية يعتبر مفهوم حديث نسبياً وعندما

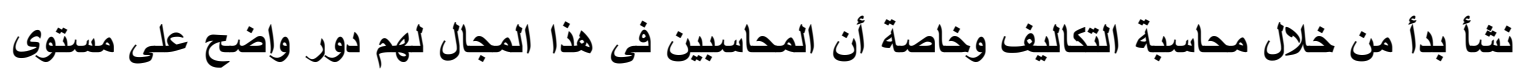
المنظمات والثركات ولديهم علاقات مختلفة مع الأفراد من داخل ومن خارج الثركات ويمكنهم استخدام

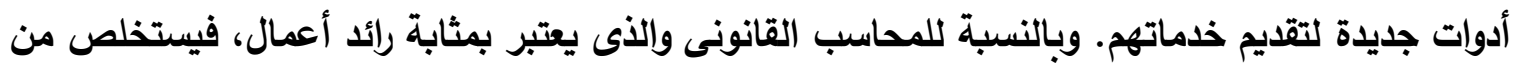
الدراسات السابقة أنه ينطبق عليه مهارات رائد الأعمال من حيث القدرة على القيادة والعمل من خلال

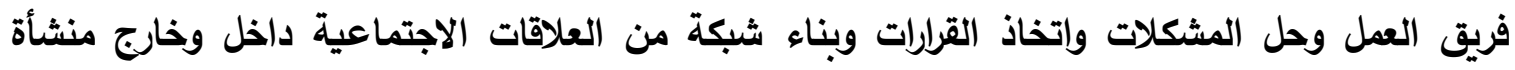


المحاسبة وإمكانية تظوير مهاراته اعتماداً على تكنولوجيا المعلومات لتقديم خدماته التقليدية وابتكار خدمات جديدة. ولا شك أن للجامعات دور كبير لتعليم خريجيها من المحاسبين المهارات الواجب توافرهائها وذلك من خلال تعديل مناهجها الدراسية لتدمج تلك المهارات.

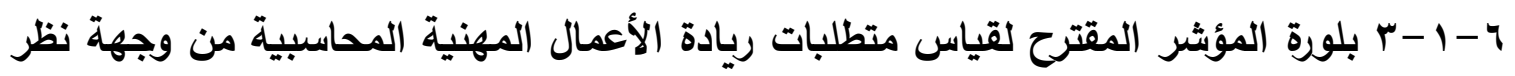
أصحاب المصالح واشتقاق فرض البحث هناك اتفاق بين الدراسات السابقة على أهية الدور الذى تلعبه مهنة المحاسبة من خلال توفير معلومات موثوق فيها لمتخذى القرارات بما يسهم فى رفاهية المجتمع (Barth, 2018). وعليه، فإن الدور الريادى لمهنة المحاسبة يعتبر دور جوهرى من وجهة نظر أصحاب المصالح المختلفين. وبالنسبة لقياس

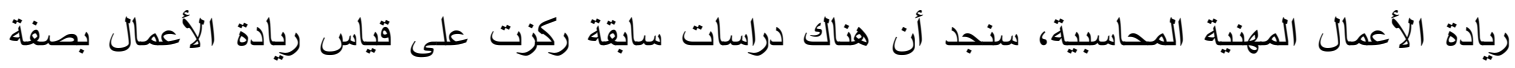

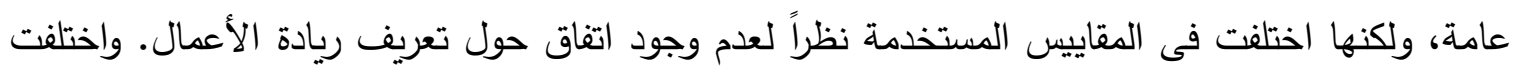
هذه الدقاييس ما بين نسبة التوظيف الذاتى، نسبة الأعمال الجديدة بالمقارنة بإجمالى وحدات الأعمال،

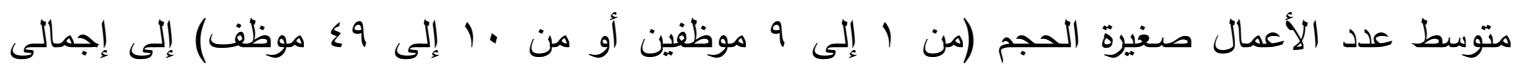
وحدات الأعمال (Godin, Clemens \& Veldhuis, 2008).ومن ناحية أخرى، يمكن التركيز على نمو الأو

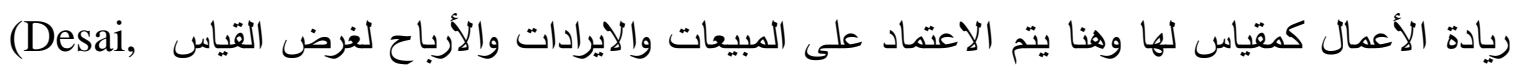
(2017. وهناك ندرة فى الدراسات التى تناولت ريادة الأعمال المهنية المحاسبية على وجه الخصوص. ونظراً لحداثة الموضوع، فإنه يمكن تطوير مؤشر لقياس متطلبات ريادة الأعمال المهنية المحاسبية استناداً إلى مؤشر ريادة الأعمال بصفة عامة.

ويمكن تناول قياس ريادة الأعمال المهنية المحاسبية من منظور أصحاب المصالح فى منشآت الصات

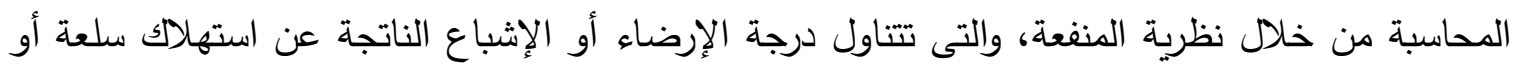

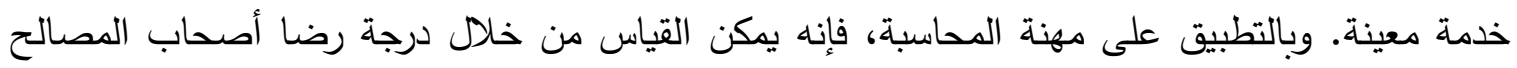
عن تثكيلة خدمات ومسئوليات المهنة والقائعين عليها وذلك من خلال تضييق فجوة التوقعات بين ما يتوقعه

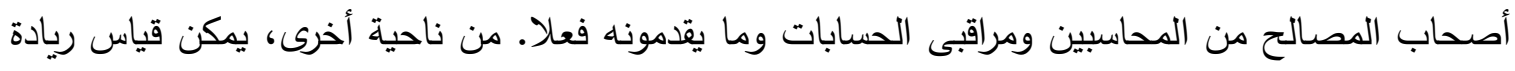

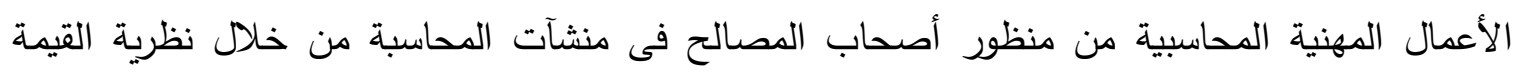
المضافة والتى تركز على القيمة الإضافية التى خلقت خلال مرحلة معينة من مراحل الانتاج أو التسويق.

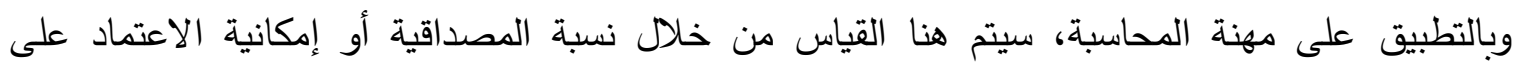
خدمات مهنة المحاسبة، وهو ما ينطبق تماماً على المغزى من وراء وجود مهنة المحاسبة وهو أن تكون مضيفة للقيمة.

كما يمكن القول أن قياس ريادة الأعمال المهنية المحاسبية من وجهة نظر أصحاب المصالح يمكن

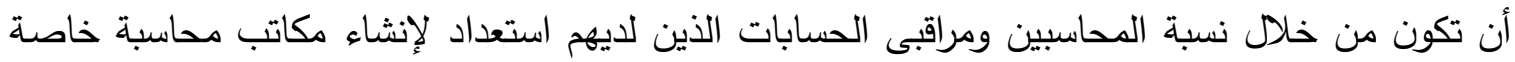


بهم، فمن المفترض أن نجاح هذا المفهوم سينعكس إيجاباً على مدى الاستعداد من قبل المحاسبين ومراقبى الحسابات الذين تتوافر لديهم مهارات القيادة والإدارة وغيرها على انثاء عملهم الخاص. ومن ناحية أخرى، يمكن قياس ريادة الأعمال المهنية المحاسبية من خلال نسبة الحصة السوقية للمحاسبين ومراقبى الحسابات

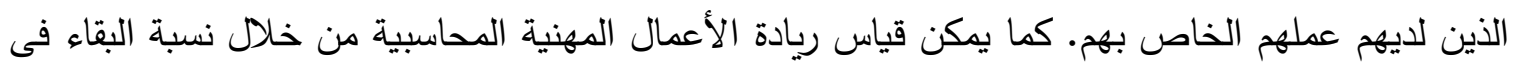
مهنة المحاسبة، وذلك يمكن أن تكون من خلال عدد السنوات على سبيل المثال. ويمكن القول أيضاً أن محددات ريادة الأعمال المهنية المحاسبية لا تختلف فى جوهرها عن أى أعمال

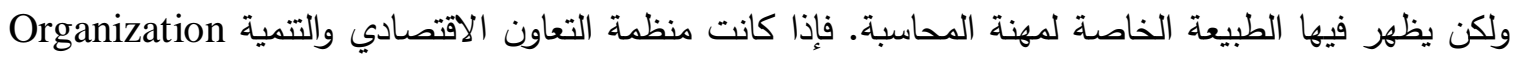
(أشارت إلى محددات ريادة الأعمال بصفة عامة من خلال الهيكل التظيمي، البحوث والتطوير والتكنولوجيا، إمكانات رائد الأعمال، الثقافة، والظروف السوقية، فإننا نجد أن هذه المحددات تتطبق على مهنة المحاسبة. فمن ناحية الهيكل التنظيمي، فلاشك أن سياسات وإجراءات مكتب المحاسبة المتعلقة بالترقيات وبرامج التدريب وتقسيم العمل والاختصاصات ومدى وجود دستور واضح لسلوكيات وأخلاق المهنة والرقابة على الجودة

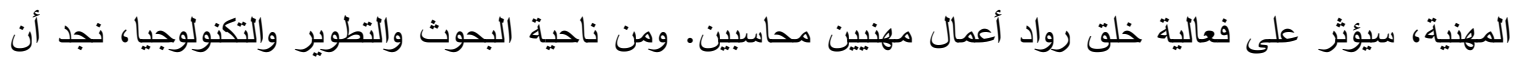
مدى تدريب المحاسبين على استخدام التكنولوجيا في عملهم وعند تخطيط وجمع أدلة المراجعة وأيضاً مدى استخدامهم للأساليب الاككترونية مثل أدوات دعم القرار ونظم الخبيرة وغيرها سيساعد فى خلق رواد أعمال محاسبين مواكبين

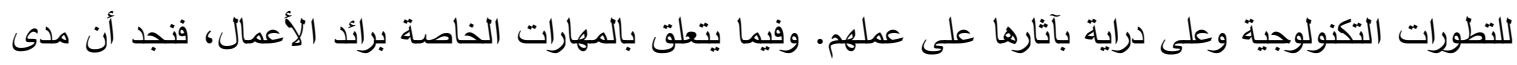

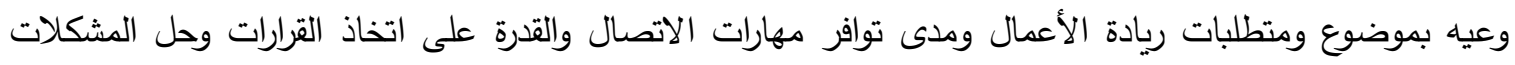
وتثكيل فريق عمل مهني سيساعد على وجود رواد أعمال محاسبين. وبالنسبة للثقافة، فإن النظرة الإيجابية لمهنة المحاسبة من قبل المجتمع وإقناع الأطراف المختلفة على أنها مضيفة للقيمة وتسهم فى رفاهية المجتمع سيحسن من ونسين فرصة وجود رواد أعمال مهنيين محاسبين. وأخيراً، فإن الظروف السوقية، من خلا عدد المكاتب التى تقدم خدمات المراجعة والفحص المحدود والخدمات الأخرى بخلاف المراجعة والثراكة مع المكاتب الأخرى وأيضاً مدى وجود قيود على دخول مكاتب جديدة فى مجال المحاسبة، سيؤثر على إمكانية وجود رواد أعمال مهنيين محاسبين. وبناء على التحليل السابق، قام الباحثان ببلورة مؤشر لمتطلبات ريادة الأعمال المهنية المحاسبية بما يتلاءم مع طبيعة مهنة المحاسبة، وهو ما سوف يعرضده الباحثان في القسم التالي للبحث. والسؤال هنا هل تستوفى مكاتب المحاسبة فى مصر، بما فى ذلك الإطار التظيمي الذى يعمل تحت ظله مراقبو

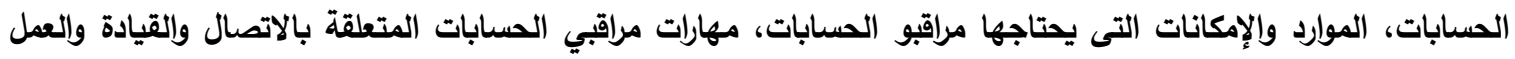

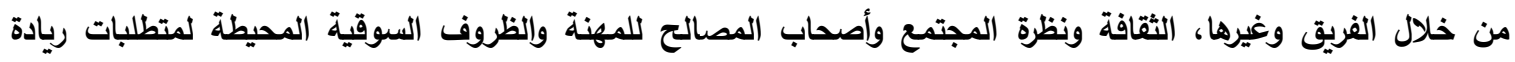

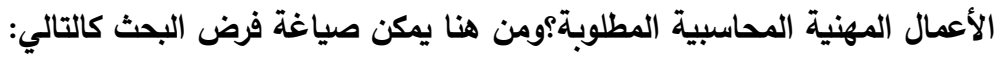
ف ا : تستوفى مكاتب المحاسبة في مصر متطلبات ربادة الأعمال المهنية المحاسبية Y 
نعرض فى هذا القسم أهداف وتوصيف الدراسة الميدانية، الإحصاءات الوصفية، وأخيراً الاختبارات الإحصائية اللازمة لاختبار فرض البحث وتحليل نتائجه، وذلك على النحو التالي: צ - 1 أهداف وتوصيف الدراسة الميدانية

تستهدف الدراسة الميدانية قياس مدى استيفاء مراقبى الحسابات فى مصر للتطلبات البات ريادة الأعمال المهنية المحاسبية. قام الباحثان بالاعتماد على قائمة مرجعية فى سياق استبيان تضمّن فى قسمه الأول بعض البيان البانيات الثخصية للمشتركين فى الدراسة، وتضمنت تلك البيانات الثخصية: السن، المركز الوظيفى (شريك - مدير مراجعة

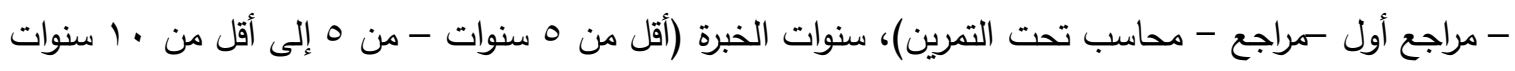
- من · 1 إلى 10 سنة - أكثر من 10 سنة)، مجالات الخبرة (أعمال إمساك الدفاتر للعملاء - أعمال إعداد القوائم

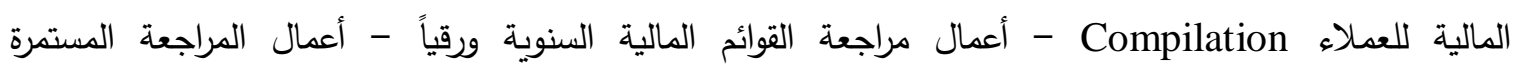
مالعمال الفحص المحدود ربع السنوى الورقى - أعمال الفحص المحدود المستمر - Continuous Auditing ألداء - Continuous Limited Review

المهنية التى حصل عليها.

واشتمل القسم الثانى من الاستبيان على بنود الدراسة، والتى انقسمت إلى ستة أقسام وهى: الإطار

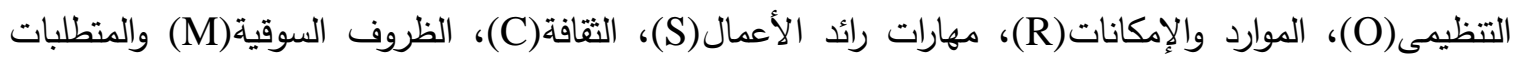
الإضافية (انظر ملحق الدراسة).

لضمان مصداقية المشتركين فى الدراسة، قام الباحثان بصياغة معظم البنود فى شكل إيجابى (أى فى إتجاه

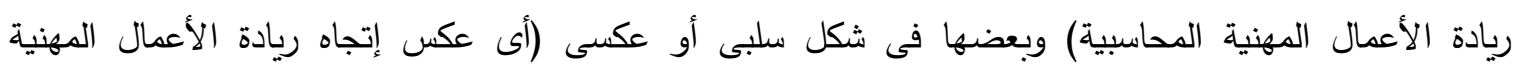

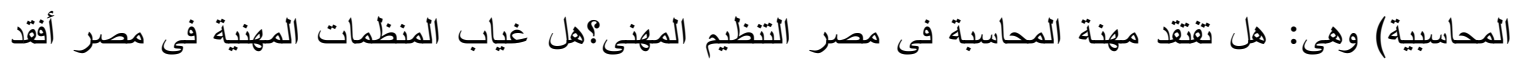

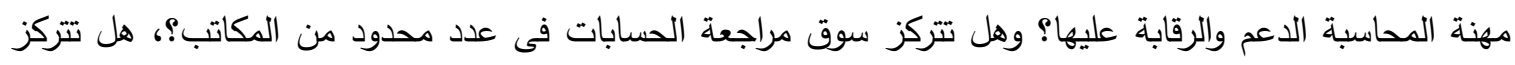

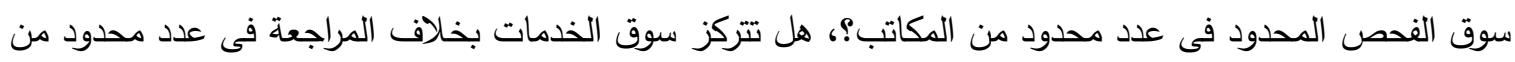

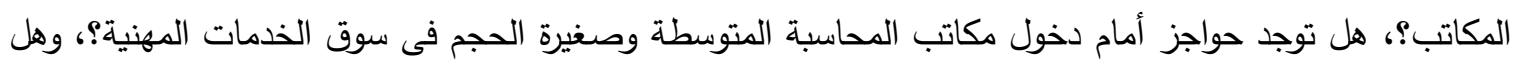
توجد عوائق وقيود قانونية تحد من نمو مكاتب المحاسبة الصغيرة؟ وقد روعى ذلك عند إدخال البيانات المتعلقة بهذه البنود.

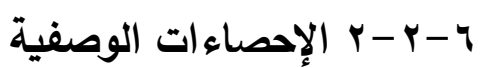

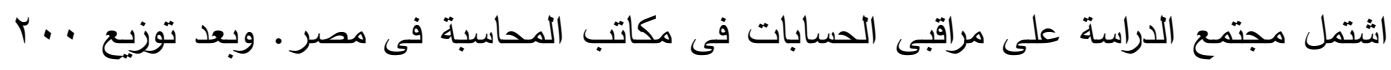

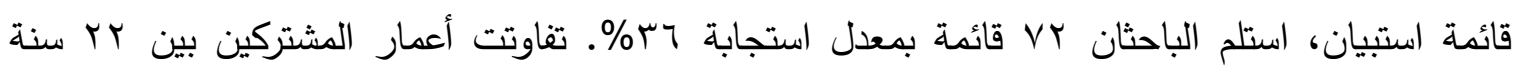

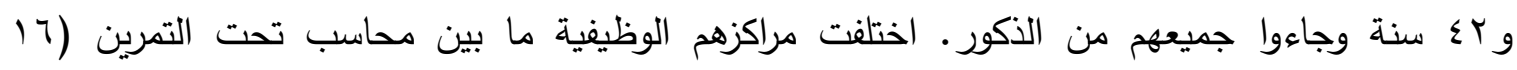

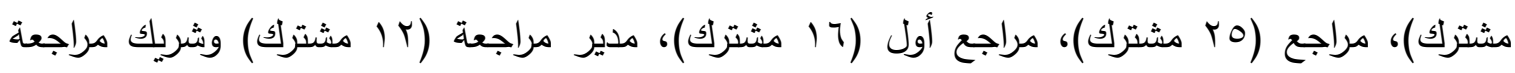

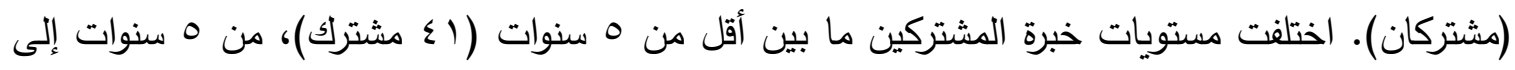

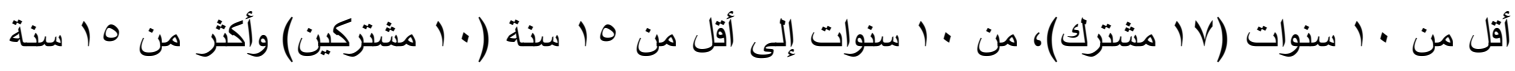
(ع مشتركين) (جدول رقم (). كما تتوعت مجالات الخبرة بين المشتركين فى الدراسة ولكن تركز معظمها 
فى أعمال المراجعة المستمرة ويليها أعمال مراجعة القوائم المالية السنوية ورقياً. وبالنسبة للمؤهل العلمى والثهادات المهنية، فتركزت معظمها فى بكالوريوس المحاسبة وبعض من المشتركين يحملون شهادات مهنية مثل

جدول (1) الإحصاءات الايموغرافية لعينة الدراسة

\begin{tabular}{|c|c|c|}
\hline النسبة المئوية & العدد & \\
\hline & & النوع \\
\hline$\% 1 \ldots$ & VY & ذكر \\
\hline$\%$ & صفر & انثى \\
\hline \multirow[t]{2}{*}{$\% 1 \ldots$} & $V Y$ & الإجمالى \\
\hline & & المركز الوظيفى \\
\hline$\% r r, r$ & 17 & محاسب تحت التمرين \\
\hline$\% r \varepsilon, \vee$ & ro & مراجع \\
\hline$\%$ \%r,Y & 17 & مراجع أول \\
\hline$\% \backslash 7, \vee$ & IT & مدير مراجعة \\
\hline$\% \curlyvee, \wedge$ & r & شريك مراجعة \\
\hline \multirow[t]{2}{*}{$\% 1 \ldots$} & Vr & الإجمالى \\
\hline & & سنوات الخبرة \\
\hline$\% 07,9$ & $\varepsilon 1$ & أقل من ه سنوات \\
\hline \% rr, & iv & من ه إلى أقل من • 1 سنوات \\
\hline$\% \backslash r, q$ & 1. & من · ا إلى أقل من 10 سنة \\
\hline$\% 0,7$ & $\varepsilon$ & أكثر من 10 سنة \\
\hline$\% 1 \ldots$ & $V Y$ & الإجمالى \\
\hline
\end{tabular}

؟-r - بالاختبارات الإحصائية وتحليل نتائج الدراسة

تم إجراء اختبار للتحقق من مدى إمكانية الاعتماد على البيانات الواردة من المشاركين فى الدراسة

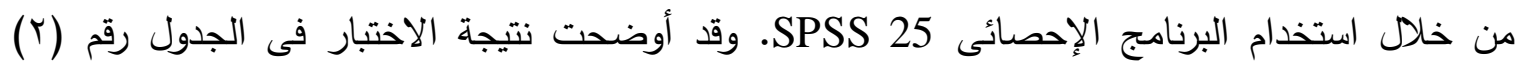

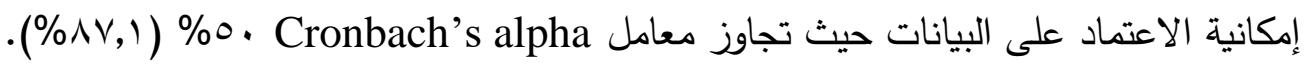
جدول (ץ) نتيجة اختبار الاعتمادية

\begin{tabular}{|c|c|c|}
\hline معامل Cronbach’s Alpha & عدد البنود & \\
\hline$\% \wedge \vee, 1$ & $7 \wedge$ & عينة الدراسة \\
\hline
\end{tabular}

وللتحقق من مدى صحة البنود المستخدمة لقياس متطلبات ريادة الأعمال المهنية المحاسبية، تم احتساب درجة score لكل مشترك وهو مجموع الإجابات بالإيجاب أو القبول لكل مشترك على البنود الواردة فى القائمة المرجعية (مؤشر لمابه 
متطلبات ريادة الأعمال المهنية المحاسبية). بعد ذلك تم إجراء اختبار ارتباط ثنائى Pearson bivariate correlation بين الردود على كل بند وإجمالى الدرجة المحتسبة أو مؤشر متطلبات ريادة الأعمال المهنية المحاسبية.

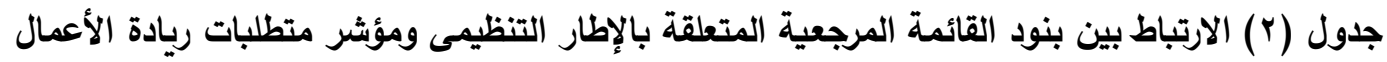

المهنية المحاسبية

\begin{tabular}{|c|c|c|c|c|c|}
\hline & & Score & & & Score \\
\hline \multirow[t]{3}{*}{01} & Pearson Correlation & 0.118 & 010 & Pearson Correlation & 0.124 \\
\hline & Sig. (2-tailed) & 0.328 & & Sig. (2-tailed) & 0.303 \\
\hline & $\mathrm{N}$ & 71 & & $\mathrm{~N}$ & 71 \\
\hline \multirow[t]{3}{*}{02} & Pearson Correlation & 0.497 & 011 & Pearson Correlation & 0.640 \\
\hline & Sig. (2-tailed) & 0.000 & & Sig. (2-tailed) & 0.004 \\
\hline & $\mathrm{N}$ & 72 & & $\mathrm{~N}$ & 71 \\
\hline \multirow[t]{3}{*}{03} & Pearson Correlation & 0.331 & 012 & Pearson Correlation & 0.540 \\
\hline & Sig. (2-tailed) & 0.005 & & Sig. (2-tailed) & 0.000 \\
\hline & $\mathrm{N}$ & 69 & & $\mathrm{~N}$ & 69 \\
\hline \multirow[t]{3}{*}{04} & Pearson Correlation & 0.481 & 013 & Pearson Correlation & 0.347 \\
\hline & Sig. (2-tailed) & 0.000 & & Sig. (2-tailed) & 0.003 \\
\hline & $\mathrm{N}$ & 72 & & $\mathrm{~N}$ & 72 \\
\hline \multirow[t]{3}{*}{05} & Pearson Correlation & 0.327 & 014 & Pearson Correlation & 0.390 \\
\hline & Sig. (2-tailed) & 0.006 & & Sig. (2-tailed) & 0.001 \\
\hline & $\mathrm{N}$ & 69 & & $\mathrm{~N}$ & 72 \\
\hline \multirow[t]{3}{*}{06} & Pearson Correlation & 0.522 & 015 & Pearson Correlation & 0.384 \\
\hline & \begin{tabular}{l|l} 
Sig. (2-tailed) \\
\end{tabular} & \begin{tabular}{l|l} 
& 0.000
\end{tabular} & & \begin{tabular}{|l|l} 
& Sig. (2-tailed)
\end{tabular} & \begin{tabular}{l|l} 
& 0.001
\end{tabular} \\
\hline & $\mathrm{N}$ & 69 & & $\mathrm{~N}$ & 72 \\
\hline \multirow[t]{3}{*}{$\mathbf{0 7}$} & Pearson Correlation & 0.456 & 016 & Pearson Correlation & 0.428 \\
\hline & Sig. (2-tailed) & 0.000 & & Sig. (2-tailed) & 0.000 \\
\hline & $\mathrm{N}$ & 72 & & $\mathrm{~N}$ & 72 \\
\hline \multirow[t]{3}{*}{08} & Pearson Correlation & 0.496 & 017 & Pearson Correlation & 0.384 \\
\hline & Sig. (2-tailed) & 0.000 & & Sig. (2-tailed) & 0.001 \\
\hline & $\mathrm{N}$ & 72 & & $\mathrm{~N}$ & 69 \\
\hline \multirow[t]{3}{*}{09} & Pearson Correlation & 0.638 & 018 & Pearson Correlation & 0.477 \\
\hline & Sig. (2-tailed) & 0.000 & & Sig. (2-tailed) & 0.000 \\
\hline & $\mathrm{N}$ & 72 & & $\mathrm{~N}$ & 71 \\
\hline
\end{tabular}

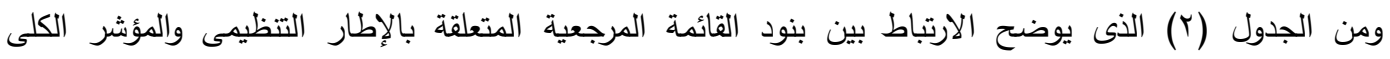

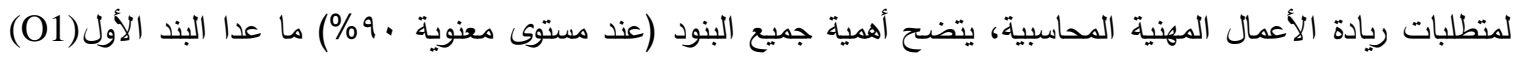
المتعلق بمدى سهولة تسجيل الحاسب تحت التمرين فى السجل العام للمحاسبين بوزارة المالية والبند العاشر (O10) المتعلق بالأثر الإيجابى للاندماج مع مكاتب أخرى على قاعدة عملاء المكتب، والخبرات فى المجالات المختلفة وفرص التدريب. جدول (r) نسبة اتفاق المشتركين على بنود القائمة المرجعية المتعلقة بالإطار التنظيمى

\begin{tabular}{|c|c|c|c|c|c|}
\hline نسبة القبول & البند & نسبة القبول & البند & نسبة القبول & البند \\
\hline $83.3 \%$ & 013 & $80.6 \%$ & 07 & $77.8 \%$ & 01 \\
\hline $93.1 \%$ & 014 & $76.4 \%$ & 08 & $84.7 \%$ & $\mathrm{O2}$ \\
\hline $84.7 \%$ & 015 & $69.4 \%$ & O9 & $84.7 \%$ & $\mathbf{O 3}$ \\
\hline $87.5 \%$ & 016 & $76.4 \%$ & $\mathbf{0 1 0}$ & $77.8 \%$ & O4 \\
\hline $68.1 \%$ & 017 & $86.1 \%$ & 011 & $81.9 \%$ & 05 \\
\hline $83.3 \%$ & 018 & $62.5 \%$ & 012 & $79.2 \%$ & O6 \\
\hline
\end{tabular}


ولتحديد مدى اتفاق مراقبى الحسابات فى مكاتب المحاسبة فى مصر على متطلبات الإطار التظيمى المحددة لريادة

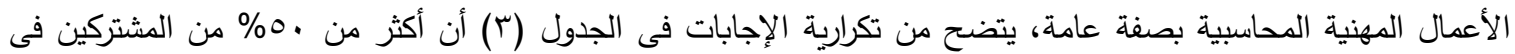
الدراسة يتفقون على تلك المتطلبات والتى تتعلق بسهولة التسجيل فى السجل العام للدحاسبين بوزارة المالية وأن مكاتب المحاسبة

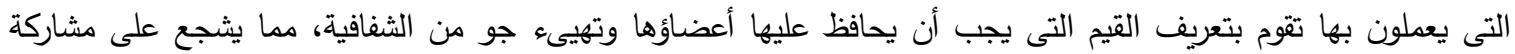

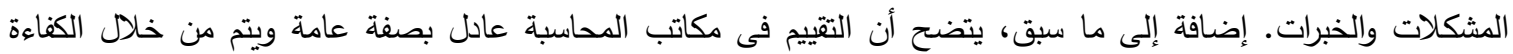
والإتقان وأن سياسة الترقية تقوم على أساس المهارات والخبرات. كما يطبق المكتب سياسة اتصال فعالة ويتبنى دستور لأخلاقيات الأعمال المهنية ولديه استراتيجية لتتمية حصته السوقية.

جدول ( ) الارتباط بين بنود القائمة المرجعية المتعلقة بالإمكانات والموارد ومؤشر متطلبات ريادة الأعمال المهنية المحاسبية

\begin{tabular}{|c|c|c|c|c|c|}
\hline & & Score & & & Score \\
\hline \multirow[t]{3}{*}{ R1 } & Pearson Correlation & 0.494 & R7 & Pearson Correlation & 0.374 \\
\hline & Sig. (2-tailed) & 0.000 & & Sig. (2-tailed) & 0.001 \\
\hline & $\overline{\mathrm{N}}$ & 72 & & $\bar{N}$ & 71 \\
\hline \multirow[t]{3}{*}{$\mathbf{R 2}$} & Pearson Correlation & 0.510 & R8 & Pearson Correlation & 0.556 \\
\hline & Sig. (2-tailed) & 0.000 & & Sig. (2-tailed) & 0.000 \\
\hline & $\mathrm{N}$ & 72 & & $\mathrm{~N}$ & 71 \\
\hline \multirow[t]{3}{*}{$\mathbf{R 3}$} & Pearson Correlation & 0.686 & R9 & Pearson Correlation & 0.373 \\
\hline & Sig. (2-tailed) & 0.000 & & Sig. (2-tailed) & 0.001 \\
\hline & $\mathrm{N}$ & 72 & & $\mathrm{~N}$ & 71 \\
\hline \multirow[t]{3}{*}{$\mathbf{R 4}$} & Pearson Correlation & 0.399 & R10 & Pearson Correlation & 0.475 \\
\hline & Sig. (2-tailed) & 0.001 & & Sig. (2-tailed) & 0.000 \\
\hline & $\mathrm{N}$ & 72 & & $\mathrm{~N}$ & 72 \\
\hline \multirow[t]{3}{*}{$\mathbf{R 5}$} & Pearson Correlation & 0.364 & R11 & Pearson Correlation & 0.557 \\
\hline & Sig. (2-tailed) & 0.002 & & Sig. (2-tailed) & 0.000 \\
\hline & $\overline{\mathrm{N}}$ & 72 & & $\mathrm{~N}$ & 68 \\
\hline \multirow[t]{3}{*}{ R6 } & Pearson Correlation & 0.314 & & & \\
\hline & Sig. (2-tailed) & 0.007 & & & \\
\hline & $\mathrm{N}$ & 72 & & & \\
\hline
\end{tabular}

ومن الجدول (ء) الذى يوضح الارتباط بين بنود القائمة المرجعية المتعلقة بالإمكانات والموارد التى

يجب توافرها لرائد الأعمال ومؤشر متطلبات ريادة الأعمال المهنية المحاسبية، يتضح معنوية جميع البنود الواردة فى الاستبيان. ويرى الباحثان من هذا الارتباط المعنوى أهمية توافر سياسة لتدريب مراقبى الحسابات وتلقيهح للتدريب الكافى على وسائل تكنولوجيا المعلومات وتطبيقهم للأدوات الحديثة التى تعتمد على الى تكنولوجيا المعلومات مثل نظم الخبيرة والتنقيب عن وتحليل البيانات فى أدائهم لعملهم.

جدول (•) نسبة اتفاق المشتركين على بنود القائمة المرجعية المتعلقة بالإمكانات والموارد

\begin{tabular}{|c|c|c|c|c|c|}
\hline نسبة القبول & البند & نسبة القبول & البند & نسبة القبول & البند \\
\hline $87.5 \%$ & R9 & $87.5 \%$ & R5 & $77.8 \%$ & R1 \\
\hline $83.3 \%$ & R10 & $61.1 \%$ & R6 & $79.2 \%$ & $\mathbf{R 2}$ \\
\hline $25.5 \%$ & R11 & $91.7 \%$ & R7 & $59.7 \%$ & R3 \\
\hline
\end{tabular}




\begin{tabular}{|l|l|l|l|l|l|}
\hline & & $61.1 \%$ & $\mathbf{R 8}$ & $83.3 \%$ & R4 \\
\hline
\end{tabular}

وللتحقق من مدى اتفاق مراقبى الحسابات على متطلبات الإمكانات والموارد اللازمة لريادة الأعمال المهنية المحاسبية بصفة عامة، يتضح من تكرارية الإجابات فى الجدول (0) أن أكثر من • 0\% من المشتركين لديهم خبرة

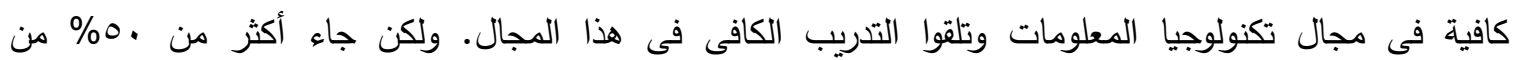
المشتركين ليشيروا إلى عدم تلقيهم التدريب على المراجعة من خلال سلسلة الكتل(R11)، وهى من أنظمة تكنولوجيا المعلومات والتى يتم استخدامها دولياً، وبالتالى من المفترض أن يكون لدى مراقبى الحسابات خبرة كافية عن كيفية مراجعة تلك الاتجاهات الحديثة والتعامل معها.

جدول (†) الارتباط بين بنود القائمة المرجعية المتعلقة بمهارات رائد الأعمال ومؤشر متطلبات ريادة

الأعمال المهنية المحاسبية

\begin{tabular}{|c|c|c|c|c|c|}
\hline & & Score & & & Score \\
\hline \multirow[t]{3}{*}{ S1 } & Pearson Correlation & 0.354 & S12 & Pearson Correlation & 0.148 \\
\hline & Sig. (2-tailed) & 0.002 & & Sig. (2-tailed) & 0.215 \\
\hline & $\mathrm{N}$ & 72 & & $\mathrm{~N}$ & 72 \\
\hline \multirow[t]{3}{*}{ S2 } & Pearson Correlation & 0.217 & S13 & Pearson Correlation & 0.091 \\
\hline & Sig. (2-tailed) & 0.067 & & Sig. (2-tailed) & 0.448 \\
\hline & $\mathrm{N}$ & 72 & & $\mathrm{~N}$ & 72 \\
\hline \multirow[t]{3}{*}{$\mathbf{S 3}$} & Pearson Correlation & 0.267 & S14 & Pearson Correlation &.$^{\mathrm{c}}$ \\
\hline & Sig. (2-tailed) & 0.024 & & Sig. (2-tailed) & . \\
\hline & $\mathrm{N}$ & 72 & & $\mathrm{~N}$ & 72 \\
\hline \multirow[t]{3}{*}{ S4 } & Pearson Correlation & 0.095 & S15 & Pearson Correlation & 0.318 \\
\hline & Sig. (2-tailed) & 0.429 & & Sig. (2-tailed) & 0.006 \\
\hline & $\mathrm{N}$ & 72 & & $\mathrm{~N}$ & 72 \\
\hline \multirow[t]{3}{*}{ S5 } & Pearson Correlation & 0.339 & S16 & Pearson Correlation & 0.089 \\
\hline & Sig. (2-tailed) & 0.004 & & Sig. (2-tailed) & 0.457 \\
\hline & $\mathrm{N}$ & 72 & & $\mathrm{~N}$ & 72 \\
\hline \multirow[t]{3}{*}{ S6 } & Pearson Correlation & 0.390 & S17 & Pearson Correlation & 0.154 \\
\hline & \begin{tabular}{l|l} 
Sig. (2-tailed)
\end{tabular} & \begin{tabular}{l|l} 
& 0.001
\end{tabular} & & \begin{tabular}{l|l} 
Sig. (2-tailed)
\end{tabular} & \begin{tabular}{l|l} 
& 0.195
\end{tabular} \\
\hline & $\mathrm{N}$ & 72 & & $\mathrm{~N}$ & 72 \\
\hline \multirow[t]{3}{*}{ S7 } & Pearson Correlation & 0.140 & S18 & Pearson Correlation & 0.409 \\
\hline & Sig. (2-tailed) & 0.241 & & Sig. (2-tailed) & 0.000 \\
\hline & $\mathrm{N}$ & 72 & & $\mathrm{~N}$ & 72 \\
\hline \multirow[t]{3}{*}{ S8 } & Pearson Correlation & 0.211 & S19 & Pearson Correlation & 0.195 \\
\hline & Sig. (2-tailed) & 0.075 & & Sig. (2-tailed) & 0.100 \\
\hline & $\mathrm{N}$ & 72 & & $\mathrm{~N}$ & 72 \\
\hline \multirow[t]{3}{*}{ S9 } & Pearson Correlation &. $\mathrm{c}$ & $\mathbf{S 2 0}$ & Pearson Correlation & 0.093 \\
\hline & Sig. (2-tailed) & . & & Sig. (2-tailed) & 0.445 \\
\hline & $\mathrm{N}$ & 72 & & $\mathrm{~N}$ & 70 \\
\hline \multirow[t]{2}{*}{ S10 } & Pearson Correlation & 0.091 & S21 & Pearson Correlation & 0.197 \\
\hline & Sig. (2-tailed) & 0.448 & & Sig. (2-tailed) & 0.099 \\
\hline
\end{tabular}




\begin{tabular}{|l|l|l|l|l|l|}
\hline & N & 72 & & N & 71 \\
\hline S11 & Pearson Correlation & 0.288 & S22 & Pearson Correlation & 0.298 \\
\hline & Sig. (2-tailed) & 0.015 & & Sig. (2-tailed) & 0.011 \\
\hline & N & 71 & & N & 72 \\
\hline
\end{tabular}

ومن الجدول (†) الذى يوضح الارتباط بين بنود القائمة المرجعية المتعلقة بمهارات رائد الأعمال ومؤشر منطلبات ريادة الأعمال المهنية المحاسبية، يتضح عدم معنوية البند الرابع (S4) والسابع (S7) والتاسع (S9) والعاشر (S10) والبنود من الثانى عشر (S12) إلى الرابع عشر (S14) والبند السادس عشر (S16) والسابع عشر (S17) العشرين (S20). ويرى الباحثان من تحليل الارتباط السابق أهمية مهارات رائد الأعمال، وأهمية أن يكون مراقب الحسابات لديه خلفية عن ريادة الأعمال بصفة عامة وريادة الأعمال المهنية المحاسبية بصفة خاصة وأن يتلقى منهجاً دراسياً خلال دراسته الجامعية ويحضر مؤتمرات فى ريادة الأعمال وذلك حتى يكون مؤهلاً لأن يكون رائد أعمال مهنى محاسبى فى المستقبل. كما يتضح أيضاً أهمية أن يكون مراقب الحسابات مقتتعاً بقضية ريادة الأعمال المهنية المحاسبية ومردودها المادى والمعنوى لهوى الإيجابى وأن يكون لايه ثقة فى قدرته على تحقيق أهدافه وتخطى الصعاب. وفى نفس السياق يجب أن يتصف فريق العمل داخل المكتب بالهرمية بحيث يعكس اختلاف الخبرات والتنوع الإدراكى الذى يوفر رؤى غير تقليدية لحل المشاكل خاصة تلك المتعلقة بالمشاكل المستحدثة وأن يساهم فى زيادة حصة مكتبه السوقية ويحرص على أداء خدمات مهنية مستحدثة لعملائه وأن يدير فريق العمل من خلال جلسات العصف الذهنى.

جدول (V) نسبة اتفاق المشتركين على بنود القائمة المرجعية المتعلقة بمهارات رائد الأعمال

\begin{tabular}{|c|c|c|c|c|c|}
\hline نسبة القبول & البند & نسبة القبول & البند & نسبة القبول & البند \\
\hline $86.1 \%$ & S17 & $100 \%$ & S9 & $80.6 \%$ & S1 \\
\hline $83.3 \%$ & S18 & $98.6 \%$ & S10 & $56.9 \%$ & S2 \\
\hline $93.1 \%$ & S19 & $98.6 \%$ & S11 & $56.9 \%$ & S3 \\
\hline $95.8 \%$ & $\mathbf{S 2 0}$ & $91.7 \%$ & S12 & $84.7 \%$ & S4 \\
\hline $63 \%$ & S21 & $98.6 \%$ & S13 & $91.7 \%$ & S5 \\
\hline \multirow[t]{3}{*}{$34.7 \%$} & S22 & $100 \%$ & S14 & $91.7 \%$ & S6 \\
\hline & & $63.9 \%$ & S15 & $80.6 \%$ & S7 \\
\hline & & $95.8 \%$ & S16 & $98.6 \%$ & S8 \\
\hline
\end{tabular}


ولتحديد مدى اتفاق مراقبى الحسابات فى مكاتب المحاسبة فى مصر على متطلبات مهارات رائد الأعمال بصفة عامة، يتضح من تكرارية الإجابات فى الجدول (V) أن أكثر من •0\% من المشتركين

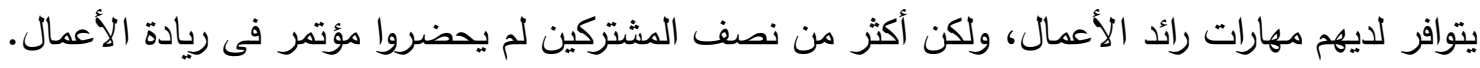
جدول (^) الارتباط بين بنود القائمة المرجعية المتعلقة بالثقافة ومؤشر متطلبات ريادة الأعمال المهنية المحاسبية لاعنية

\begin{tabular}{|l|l|l|l|l|l|}
\hline & & Score & & & Score \\
\hline C1 & Pearson Correlation & 0.349 & C5 & Pearson Correlation & 0.370 \\
\hline & Sig. (2-tailed) & 0.003 & & Sig. (2-tailed) & 0.001 \\
\hline & N & 72 & & N & 72 \\
\hline C2 & Pearson Correlation & 0.168 & C6 & Pearson Correlation & 0.366 \\
\hline & Sig. (2-tailed) & 0.159 & & Sig. (2-tailed) & 0.002 \\
\hline & N & 72 & & N & 72 \\
\hline C3 & Pearson Correlation & 0.167 & C7 & Pearson Correlation & 0.147 \\
\hline & Sig. (2-tailed) & 0.164 & & Sig. (2-tailed) & 0.217 \\
\hline & N & 71 & & N & 72 \\
\hline C4 & Pearson Correlation & 0.170 & C8 & Pearson Correlation & 0.186 \\
\hline & Sig. (2-tailed) & 0.153 & & Sig. (2-tailed) & 0.118 \\
\hline & N & 72 & \multicolumn{2}{|l|}{ N } & 72 \\
\hline
\end{tabular}

ومن الجدول (^) الذى يوضح الارتباط بين بنود القائمة المرجعية المتعقة بالثقافة ومؤشر منطلبات

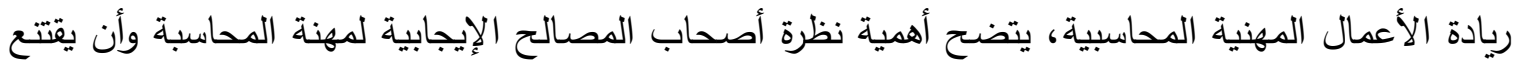
مراقب الحسابات بأنه يمارس مهنة لها قيمة مضافة للمجتمع وتسهم فى رفاهيته. جدول (9) نسبة اتفاق المشتركين على بنود القائمة المرجعية المتعلقة بالثقافة

\begin{tabular}{|c|c|c|c|c|c|}
\hline نسبة القبول & البند & نسبة القبول & البند & نسبة القبول & البند البذ \\
\hline $94.4 \%$ & C7 & $45.8 \%$ & $\mathrm{C} 4$ & $48.6 \%$ & C1 \\
\hline $95.8 \%$ & C8 & $94.4 \%$ & C5 & $19.4 \%$ & C2 سؤال عكسى \\
\hline & & $88.9 \%$ & C6 & $23.5 \%$ & C3 سؤال عكسى \\
\hline
\end{tabular}

لتحديد مدى اتفاق مراقبى الحسابات فى مكاتب المحاسبة فى مصر على منطلبات الثقافة اللازمة

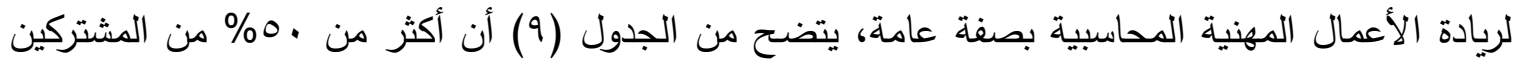

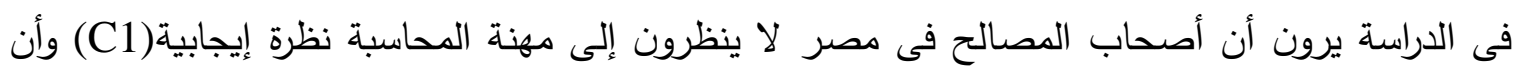
مهنة المحاسبة فى مصر تفتقد إلى التنظيم المهنى (C2) وأن غياب التنظيم المهنى أفقد المهنة الدعم والرقابة (C3)وأن المهتمين بالاتفاق مع الاتحاد العام للصناعات والاتحاد العام للغرف التجارية وهيئة الرقابة المالية لا يقومون بتنظيم ندوات تثقيفية لأصحاب المصالح حول المراجعة ودورها الحيوى فى إضفاء الثقة

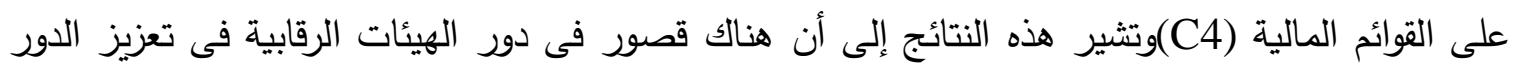
المضيف للقيمة الذى تلعبه مهنة المحاسبة لتوعية أصحاب المصالح بدورها الفعال فى الاقتصاد. 
جدول ( • ) الارتباط بين بنود القائمة المرجعية المتعقة بالظروف السوقية ومؤشر متطلبات

ريادة الأعمال المهنية المحاسبية

\begin{tabular}{|l|l|l|l|l|l|}
\hline & & Score & & & Score \\
\hline M1 & Pearson Correlation & 0.313 & M6 & Pearson Correlation & 0.095 \\
\hline & Sig. (2-tailed) & 0.007 & & Sig. (2-tailed) & 0.426 \\
\hline & N & 72 & & N & 72 \\
\hline M2 & Pearson Correlation & 0.324 & M7 & Pearson Correlation & 0.20 \\
\hline & Sig. (2-tailed) & 0.005 & & Sig. (2-tailed) & 0.076 \\
\hline & N & 72 & & N & 72 \\
\hline M3 & Pearson Correlation & 0.368 & M8 & Pearson Correlation & 0.116 \\
\hline & Sig. (2-tailed) & 0.001 & & Sig. (2-tailed) & 0.330 \\
\hline & N & 72 & & N & 72 \\
\hline M4 & Pearson Correlation & -0.053 & M9 & Pearson Correlation & 0.201 \\
\hline & Sig. (2-tailed) & 0.658 & & Sig. (2-tailed) & 0.090 \\
\hline & N & 72 & & N & 72 \\
\hline M5 & Pearson Correlation & 0.216 & & & \\
\hline & Sig. (2-tailed) & 0.069 & & & \\
\hline & N & 72 & & & \\
\hline
\end{tabular}

من الجدول (· () الذى يوضح الارتباط بين بنود القائمة المرجعية المتعلقة بالظروف السوقية لـهنة

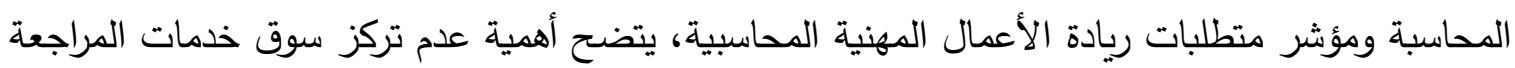
والخدمات الأخرى بخلاف المراجعة والفحص المدود فى عدد محدود من المكاتب بحيث يسهل ظهور رواد أعمال مهنيين محاسبين. كما يتضح أيضاً أهمية عدم وجود عوائق أو قيود قانونية تحد من نمو مكاتب

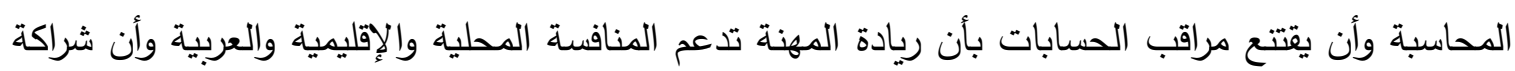

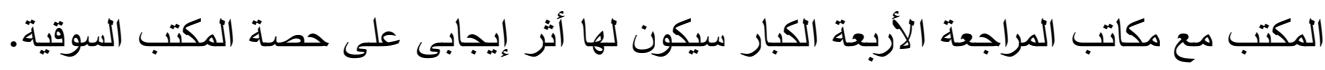

جدول (1 1 ) نسبة اتفاق المشتركين على بنود القائمة المرجعية المتعلقة بالظروف السوبة السوقية

\begin{tabular}{|c|c|c|c|c|c|}
\hline نسبة القبول & البند & نسبة القبول & البند & نسبة القبول & البند \\
\hline $79.2 \%$ & M7 & $41.7 \%$ & M4 سؤال عكسى & $11.1 \%$ & M1 سؤال عكسى \\
\hline $94.4 \%$ & M8 & $47.2 \%$ & M5 & $12.5 \%$ & M2 سؤال عكسى \\
\hline $94.4 \%$ & M9 & $80.6 \%$ & M6 & $36.1 \%$ & M3 سؤال عكسى \\
\hline
\end{tabular}

ولتحديد مدى اتفاق مراقبى الحسابات فى مكاتب المحاسبة فى مصر على المتطلبات المتعلقة بالظروف السوقية، والتى قد تثجع أو تعيق خلق رواد أعمال مهنيين، يتضح من تكرارية الاجابات فى الجدول (1) تركّز سوق مراجعة الحسابات(M1) والفحص المحدود (M2) والخدمات الأخرى بخلاف المراجعة(M3) فى عدد محدود من المكاتب، وهو ما قد يعيق خلق رواد أعمال فى مجال المحاسبة والمراجعة. 
وبعد استبعاد البنود غير الصحيحة (التى أثبتت عدم معنويتها فى مؤشر متطلبات ريادة الأعمال المهنية المحابية)، قام الباحثان بالاعتماد على البنود الصحيحة فقط للوصول إلى أهم العوامل من وجهة

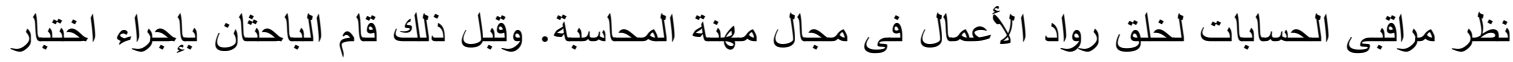

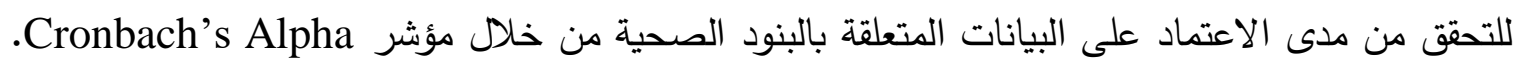

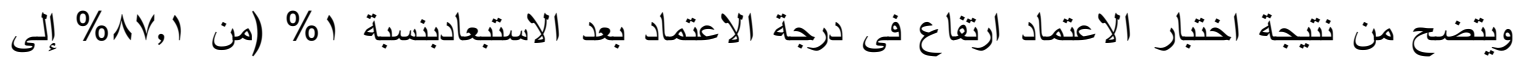

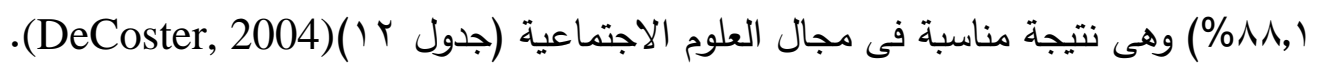
جدول (Y Y ) نتيجة اختبار الاعتمادية

\begin{tabular}{|c|c|c|}
\hline Cronbach's Alpha معامل & عدد البنود & \\
\hline$\% \wedge \wedge, 1$ & $\varepsilon \wedge$ & 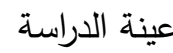 \\
\hline
\end{tabular}

ومما سبق يمكن الوصول إلى مؤشر لمتطلبات ريادة الأعمال المهنية المحاسبية ملائم لبيئة

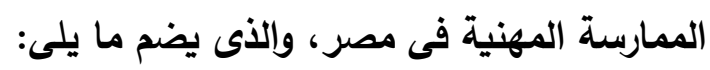
1- - 1 - الإطار التنظيمى

- - يقوم مكتب المحاسبة بتعريف القيم التى يجب أن يحافظ عليها أعضاؤه ويقوم بتطوير دستور السلوك والأخلاقيات الذى يمكن من خلاله تطبيق هذه القيم(O2)

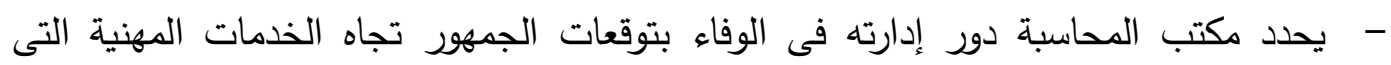

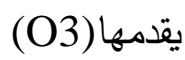

- - يقوم مكتب المحاسبة بتهيئة جو من الثفافية يشجع أعضائه على مشاركة مشكلاتهم ومعرفتهم وخبراتهم المتعلقة بالأعمال المهنية(O4) - - يتم تقسيم العمل بالمكتب بحسب الاختصاص والتتسيق بين المهام حتى يتم تحقيق أهداف

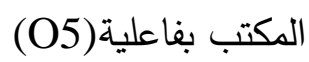

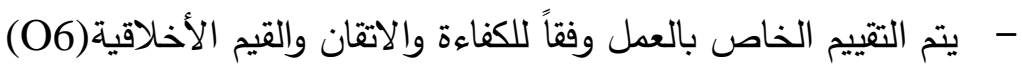
- - - يتبنى مكتب المحاسبة سياسات وإجراءات للترقية الوظيفية يكفل ترقية المراجعين الذين يملكون المهارات والخبرات اللازمة لانجاز المهام الموكلة إليهم(O7) - لاى المكتب سياسة ونظام عادل لتقييم الأداء المهنى(08) - - يطبق مكتب المحاسبة سياسة اتصال فعالة بحيث يسهل تبادل الآراء ومناقشة الأمور الجوهرية بين أعضائه(O9)

- - يتبنى مكتب المحاسبة دستور لأخلاقيات الأعمال المهنية(O11) - ل لاى المكتب استراتيجية لتتمية حصته فى سوق الخدمات المهنية(O12) - تؤدى الشراكة مع مكاتب المحاسبة الأربعة الكبار 4 Big إلى زيادة إمكانية الوصول إلى التى الخبرات الدولية والقدرة على المنافسة(O13) 
- - يقوم مكتب المحاسبة بتثجيع أعضائه ومساعدتهم على المحافظة على، وتطوير، كفاءتهم المهنية ومستوى الثك المهنى(O14)

- - مقوم مكتب المحاسبة بتطبيق، وتحديث، نظام لرقابة الجودة المهنية(O15) - - يقوم مكتب المحاسبة بتوفير بيئة تتوفر فيها المعلومات اللازمة التى تمكن المسئولين من القيام كلية بدورهم ومسئولياتهم المتعلقة بالاشراف والتثييم(O16) - - يتبنى مكتب المحاسبة فلسفة إعداد ونشر تقرير شفافية مهنية أسوة بمكاتب المحاسبة الدولية الكبرى (O17) - - يتبنى مكتب المحاسبة فلسفة تلافى ملاحظات التفتيش عليه من هيئة الرقابة المالية وغيرها من

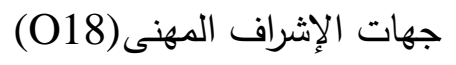

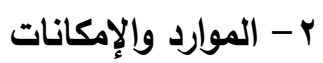

- مجود بمكتب المحاسبة سياسة معلنة للتدريب(R1)

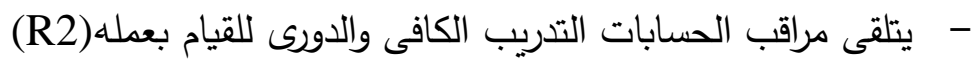
- - يتلقى مراقب الحسابات التدريب الكافى على أدوات تكنولوجيا المعلومات (R2) - يعتمد مراقب الحسابات على تكنولوجيا المعلومات بصورة أساسية فى عمله(R4) -

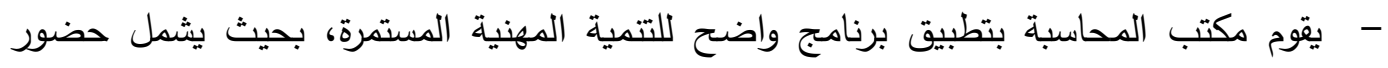

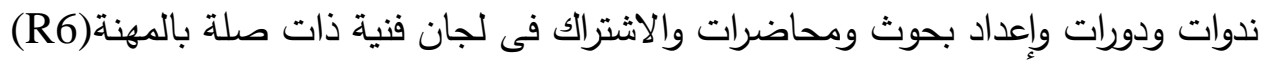

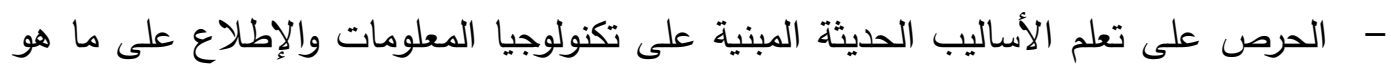

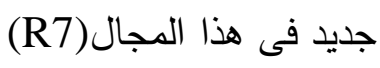
- - الاعتماد على الأساليب التكنولوجية مثل أدوات دعم القرار ، النظم الخبيرة، التتقيب عن البيانات (R8) Data Mining

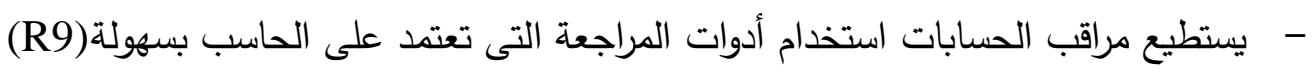

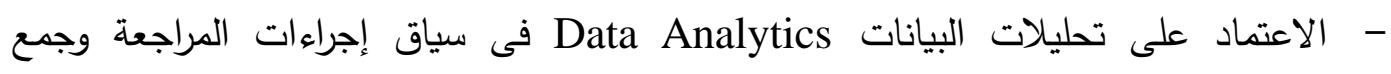
الأدلة) R10)

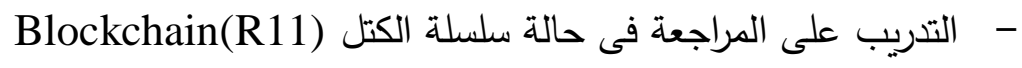
r- ب مهارات رائد الأعمال

- لاى مراقب الحسابات خلفية عن ريادة الأعمال بصفة عامة(S1) - لاعمال -

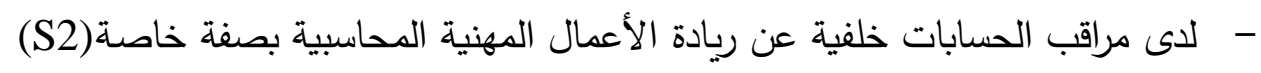
- - - يتلقى مراقب الحسابات منهجا دراسيا عن ريادة الأعمال خلال فترة دراسته الجامعية(S3) -

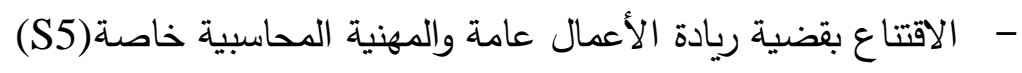


- الاقتناع بأن لريادة الأعمال المهنية المحاسبية مردود مادى ومعنوى وتنافسى مهنى(S6) -

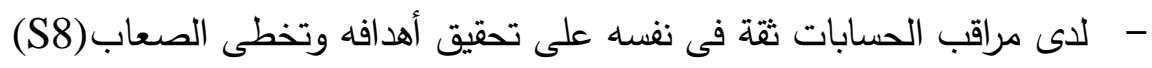

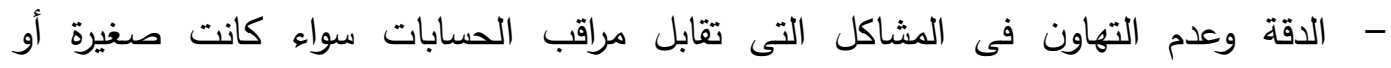
كبيرة(S11) - يتصف فريق العمل داخل المكتب بالهرمية بحيث يعكس اختلاف الخبرات والتتوع الإدراكى الذى يوفر رؤى غير تقليدية لحل المشاكل خاصة تلك المتعقة بالمشاكل المستحدثة(S15) - التخطيط لكى تكون حصة مكتب المحاسبة بالسوق فى نمو مستمر (S18)

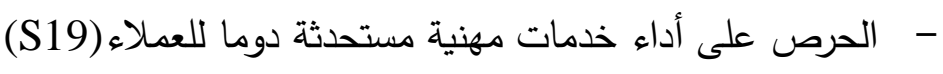

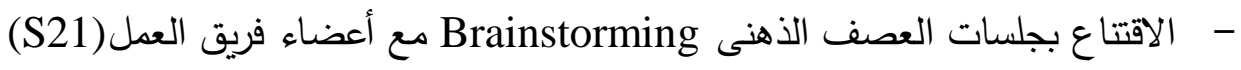
- - كضور مؤتمرات فى ريادة الأعمال بصفة عامة(S22)

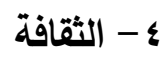

- - الاقتناع بأن مراقب الحسابات يمارس مهنة لها قيمة مضافة للجميع(C5) -

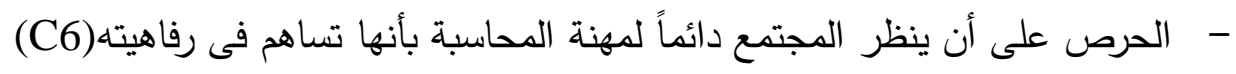
ه- - الظروف السوقية

- عدم تركز سوق مراجعة الحسابات فى عدد محدود من المكاتب(M1) -

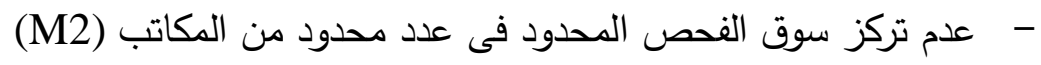
- عدم تركز سوق الخدمات بخلاف المراجعة فى عدد محدود من المكاتب (M3) -

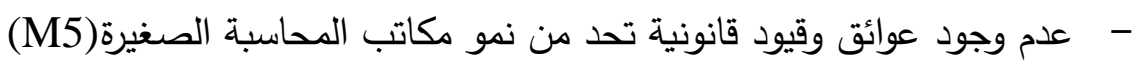
- شراكة المكتب مع إحدى مكاتب المحاسبة الأربعة الكبار مig 4 -

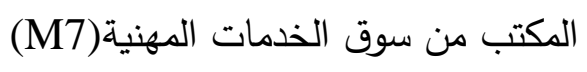

- الاقتناع بأن ريادة المهنة تدعم المنافسة المحلية والإقليمية والعربية(M9) ولاختبار فرض البحث الذى يتتاول مدى استيفاء مكاتب المحاسبة فى مصر لمتطلبات ريادة

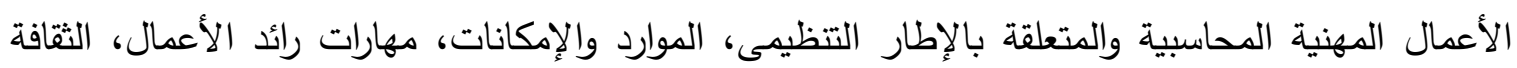
Kolomogrov - Smirnov والظروف السوقية، تم اختبار اعتدالية البيانات الواردة من خلال اختبار

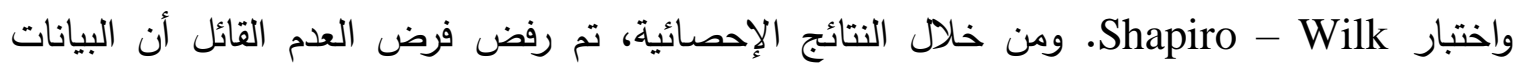
مسحوبة من مجتمع توزيعها معتدل(Sig. = 0.000). وبناء عليه، لجأ الباحثان إلى الاختبارات الإحصائية

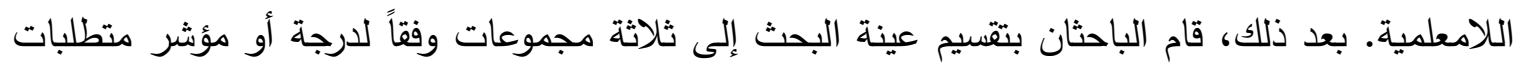

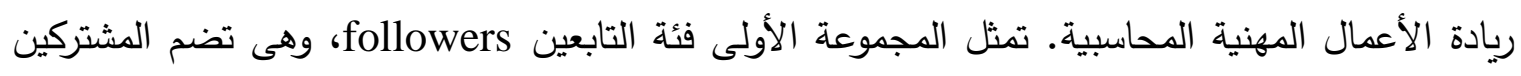

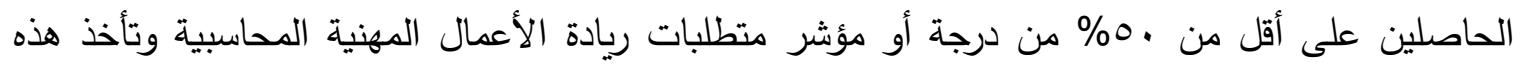




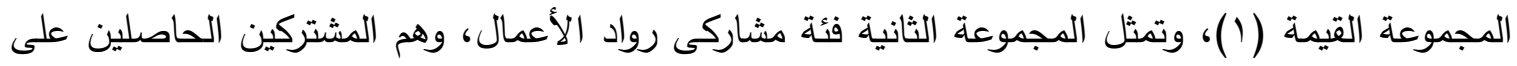
درجة أعلى من •0\% حتى •9\% لمؤشر متطلبات ريادة الأعمال المهنية المحاسبية وهم الأفراد الذين يملكون مهارات القيادة ولكنهم لا يستطيعون قيادة الأعمال وحدهم وفى حاجة إلى شركاء وتأخذ هذه الفئة

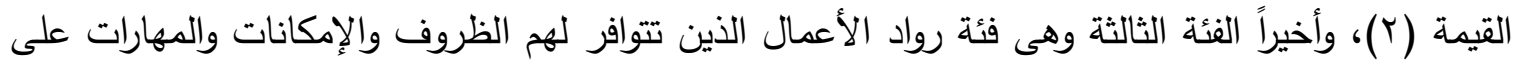

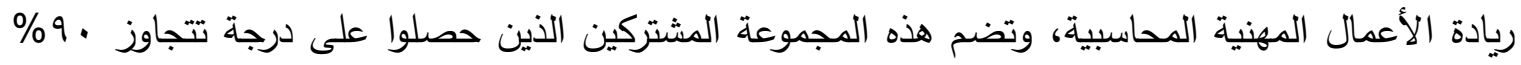

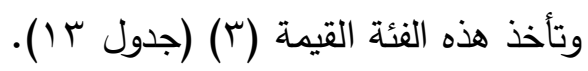

جدول (r ا ) توزيع العينة وفقاً لمؤشر متطلبات ريادة الأعمال المهنية المحاسبية

\begin{tabular}{|c|c|c|c|}
\hline النسبة & عدد المشتركين & & المجموعة \\
\hline$\% 0,4$ & $\varepsilon$ & 1 & التابعين \\
\hline$\% \vee \vee, \vee$ & 07 & r & المشاركين \\
\hline$\% 17, \vee$ & ir & $r$ & رواد الأعمال \\
\hline$\% 1 \ldots$ & Vr & & الإجمالى \\
\hline
\end{tabular}

ويتضح من الجدول (r/ ( أن نسبة رواد الأعمال المهنيين المحاسبين فى عينة الدراسة تمثل V، Y V I من إجمالي العينة وهى نسبة معقولة وتتقق مع توقعات الباحثين والدراسات السابقة. حيث تعتبر نسبة رواد الأعمال بصفة عامة منذفضة نسبياً. وللتأكد من هذه النتيجة إحصائياً، قام الباحثان باستخدام اختبار Kruskal Wallis للتحقق من مدى وجود اختلاف جوهري بين فئات العينة الثلاثة (Asymp. Sig. =0.000). ويتضح من الجدول

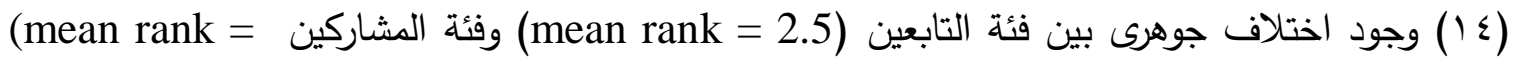
(32.51 وفئة رواد الأعمال (1) (mean rank =66.46). وباستخدام اختبار Mann Whitney لمقارنة كل فئتين على حدة، يتضح وجود اختلاف معنوى بين الفئة الأولى وهى فئة المتابعين (Mean rank = 2.5)

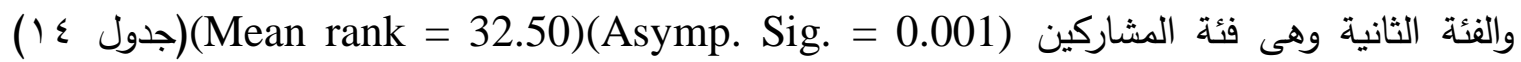
(mean rank = واختلاف معنوى بين مؤشر متطلبات ريادة الأعمال المهنية المحاسبية بين الفئة الثانية

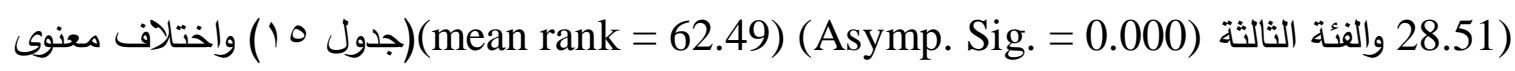
(mean rank = 10.5)(Asymp. Sig. = والثالثة (Aئ) (جدول 7 (1).

جدول (ع ا ) نتيجة اختبار Mann Whitney لمقارنة الفئة الأولى بالثانية

\begin{tabular}{|l|c|c|c|c|}
\hline & Group & N & Mean Rank & Sum of Ranks \\
\hline Score \% & 1 & 4 & 2.50 & 10.00 \\
\hline & 2 & 56 & 32.50 & 1820.00 \\
\hline Mann Whitney U & \multicolumn{5}{|c|}{0.000} \\
\hline Z & \multicolumn{5}{|c|}{-3.326} \\
\hline Asymp. Sig. (2-tailed & \multicolumn{5}{|l}{0.001} \\
\hline
\end{tabular}


جدول (0 1 ) نتيجة اختبار Mann Whitney لمقارنة الفئة الثانية بالثالثة

\begin{tabular}{|l|c|c|c|c|}
\hline & Group & N & Mean Rank & Sum of Ranks \\
\hline Score \% & 2 & 56 & 28.51 & 1596.50 \\
\hline & 3 & 12 & 62.46 & 749.50 \\
\hline Mann Whitney U & \multicolumn{5}{|c|}{0.500} \\
\hline Z & \multicolumn{5}{|c|}{-5.407} \\
\hline Asymp. Sig. (2-tailed & \multicolumn{5}{|l}{0.000} \\
\hline
\end{tabular}

جدول (1 1 ) نتيجة اختبار Mann Whitney مقارنة الفئة الأولى بالثالثة

\begin{tabular}{|l|c|c|c|c|}
\hline & Group & N & Mean Rank & Sum of Ranks \\
\hline Score \% & 1 & 4 & 2.50 & 10.00 \\
\hline & 3 & 12 & 10.50 & 126.00 \\
\hline Mann Whitney U & \multicolumn{5}{|c|}{0.000} \\
\hline Z & \multicolumn{5}{|c|}{0.993} \\
\hline Asymp. Sig. (2-tailed & \multicolumn{5}{|c|}{0.003} \\
\hline
\end{tabular}

ومن التحليل السابق، يتضح وجود اختلاف جوهرى بين الفئات الثلاث، وأن هناك اختلاف واضح بين رواد

الأعمال من ناحية والتابعين والمشاركين من ناحية أخرى. كما يتضح استيفاء رواد الأعمال المهنيين المحاسبين

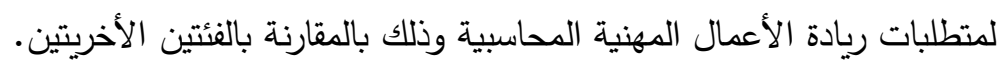

ولتحديد نسبة استيفاء مراقبى الحسابات فى مكاتب المحاسبة فى مصر للتطلبات ريادة الأعمال المهنية

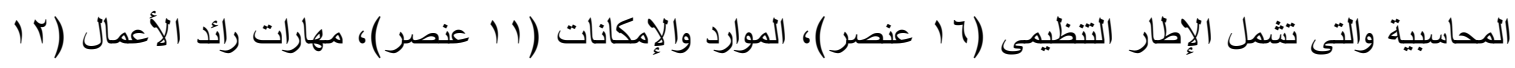

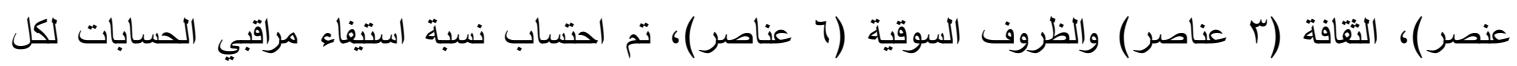

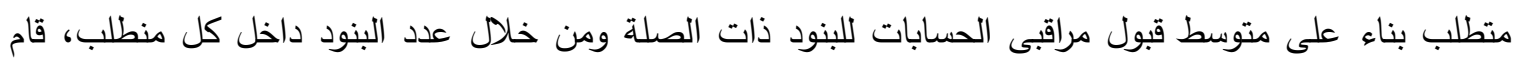
الباحثان باحتساب متوسط استيفاء مراقبى الحسابات لكل المتطلبات من خلال ترجيح كل متطلب بلاه بعدد البنود ذات ذات

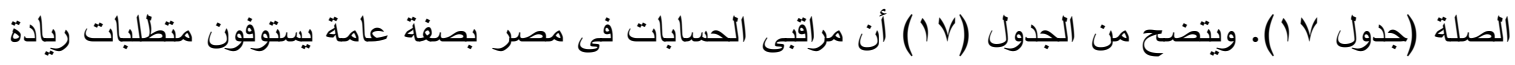

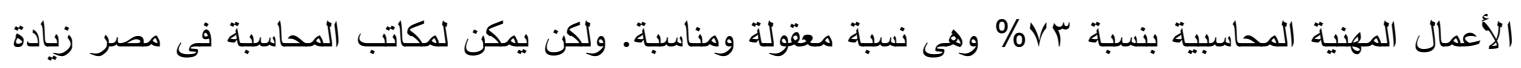
هذه النسبة من خلال التركيز على تدريب مراقبى الحسابات وخاصة فى مجال تكنولوجيا المعلومات واستخداماتها

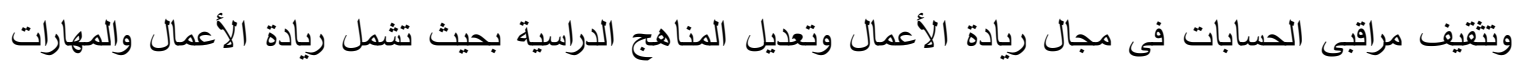

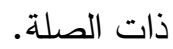

جدول ( V ) نسبة استيفاء عينة الاراسة من مراقبى الحسابات لمتطلبات ريادة الأعمال المهنية المحاسبية

\begin{tabular}{|c|c|c|}
\hline متوسط القبول & عدد البنود & متطلب ريادة الأعمال المهنية المحاسبية \\
\hline$\% \wedge \cdot, r)$ & 17 & الإطار التنظيمى \\
\hline \%Yr,OY & 11 & الموارد والإمكانات \\
\hline$\% \vee 4, . \wedge$ & ir & مهارات رائد الأعمال \\
\hline$\% \vee \vee, r$ & r & الثقافة \\
\hline$\% \leqslant 7, \vee 0$ & 7 & الظروف السوقية \\
\hline
\end{tabular}




\section{$\% \vee r, .0$}

وبناء على ما سبق، يمكن قبول فرض البحث القائل بأن مكاتب المحاسبة فى مصر تستوفى

(Schoch \& Teoh, متطلبات ريادة الأعمال المهنية المحاسبية. وتتفق هذه النتيجة مع الدراسات السابقة 1995; Law \& Hung, 2009; Sharma, Lawrence \& Lowe, 2014; Murigi, 2016) أكدت على إمكانية قيام المحاسب بصفة عامة بدور رائد الأعمال، نظراً لما يمتلكه من مهارات وإمكانيات تمكنه من الوفاء بدوره وحرصه على تكوين علاقات مع الأطراف المختلفة. ويرى الباحث أن مكاتب المحاسبة فى مصر تستوفى متطلبات ريادة الأعمال المهنية المحاسبية وذلك من خلال تركيزها على تدريب مراقبى الحسابات على استخدام تكنولوجيا المعلومات وحرصها على خلق جو من الثفافية وتبادل الآراء لحل المشكلات والعمل على توعيتهم بدورهم الرائد فى مجال المحاسبة والمراجعة. تحليل إضافى

قام الباحثان بعد ذلك باختبار أثر الخبرة على مدى استيفاء مراقبى الحسابات فى مصر لمؤشرات ريادة الأعمال المهنية المحاسبية. وقد تم قياس الخبرة(وهو متغير ترتيبى) بحيث يتضمن ع درجات، حيث

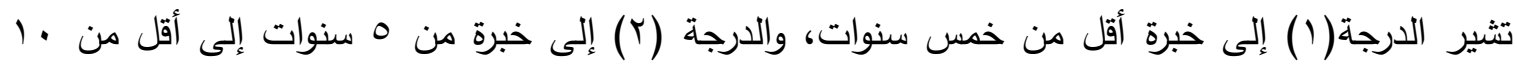
سنوات، والدرجة(ب) إلى خبرة من • 1 سنوات إلى أقل من 10 سنة، وأخيراً الدرجة (ع) إلى خبرة أكثر من 10 سنة على مؤشر متطلبات ريادة الأعمال المهنية المحاسبية من خلال تحليل انحدار بسيط كالتالى: Score $=\beta_{0}+\beta_{1}$ Experience $+\varepsilon$

وتشير نتائج تحليل الانحدار فى جدول (T (1) إلى معنوية متغير الخبرة فى مؤشر متطلبات ريادة الأعمال المهنية المحاسبية، فكلما زاد مستوى خبرة مراقب الحسابات يزيد احتمال كونه رائد للأعمال المهنية المحاسبية. وتوضح

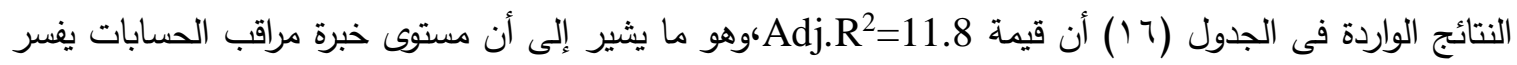

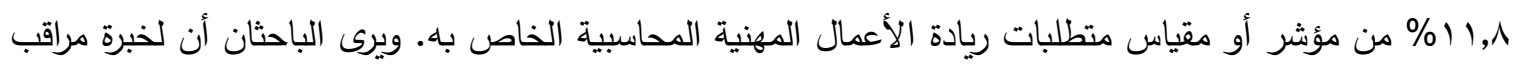
الحسابات تأثير واضح على مدى استيفائه لمتطلبات ريادة الأعمال المهنية المحاسبية، فكلما زادت خبرة مراقب لهاتب الحسابات فى مجال المحاسبة، كلما كان أكثر اطلاعاً على ما هو جديد فى مجال المحاسبة وتكنولوجيا المعلومات وكيفية استخدامها فى عمله، وكلما كان أكثر وعياً بدوره الرائد فى مجال المحاسبة وفى عملية اتخاذ القرار من قبل هلي فئل أصحاب المصالح المختلفين. جدول (7 1 ) نتائج نموذج الانحدار البسيط لاختبار أثر خبرة مراقب الحسابات على مؤشر متطلبات ريادة الأعمال المهنية المحاسبية

\begin{tabular}{|c|c|c|c|c|c|}
\hline & $\begin{array}{c}\text { Unstandardized } \\
\boldsymbol{\beta}\end{array}$ & $\begin{array}{c}\text { Std. } \\
\text { Error }\end{array}$ & $\mathbf{t}$ & Sig. & VIF \\
\hline Constant & 0.636 & 0.036 & 17.918 & 0.000 & \\
\hline EXPERIENCE & 0.060 & 0.019 & 3.239 & 0.002 & 1.000 \\
\hline Adj-R ${ }^{2}$ & \multicolumn{5}{|c|}{0.118} \\
\hline F-Stat & \multicolumn{5}{|c|}{0.493} \\
\hline Sig. & \multicolumn{5}{|c|}{0.002} \\
\hline
\end{tabular}




\section{Durbin-Watson} 1.591

\section{4-"rالخلاصة والتوصيات ومجالات البحث المقترحة}

استهدف البحث دراسة والتحقق من مدى قناعة واستيفاء مراقبى الحسابات فى مصر لمتطلبات ريادة الأعمال المهنية المحاسبية من خلال مؤشر يوضح محددات رائد الأعمال فى المجال المحاسبى. ولتحقيق هدف البحث، قام الباحثان باستعراض وتحليل الدراسات السابقة التى تتاولت مفهوم ومقاييس ريادة الأعمال بصفة عامة وريادة الأعمال المهنية المحاسبية بصفة خاصة بهدف التوصل إلى مؤشر لريادة الأعمال المهنية المحاسبية يتتاسب وطبيعة المهنة.

\section{وبعد إجراء الاختبارات الإحصائية اللازمة، توصل الباحثان إلى ما يلى:}

- مؤشر لمتطلبات ريادة الأعمال المهنية المحاسبية يضم خمسة أقسام وهى: الإطار التظظيمى الإسى ويتناول سياسة المكتب المتعلقة بالترقية والاتصال والثفافية ودستور الأخلاقيات ونظام التقييم ورقابة الجودة (7 ا بند)، الموارد والإمكانات وتتعلق بمدى تدريب مراقبى الحسابات على استخدام تكنولوجيا المعلومات فى أدائهم لعملهم (1 (1 بند)، مهارات رائد الأعمال وتركّز على فلى فئ مدى ثقة مراقب الحسابات فى نفسه وتأهيله فى مجال ريادة الأعمال من خلال تلقيه منهجاً

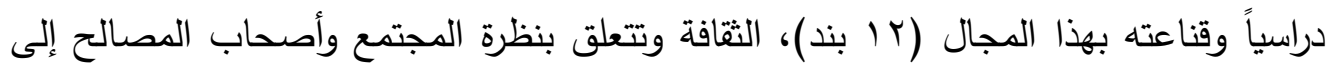
مهنة المحاسبة (ب بنود)، وأخيراً الظروف السوقية وتتعلق بمدى تركز خدمات المراجعة

$$
\text { والخدمات الأخرى فى عدد محدود من مكاتب المحاسبة (7 بنود). }
$$

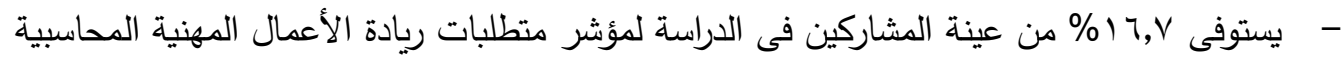

- - هناك قصور فى تدريب مراقبى الحسابات فى مصر على مراجعة سلسلة الكتل - - هناك قصور فى حضور مراقبى الحسابات فى مصر لمؤتمرات ريادة الأعمال - - هناك تركز فى خدمات المراجعة والفحص المحدود والخدمات الأخرى بخلاف المراجعة فى مرلى

$$
\text { وعليه، أوصى الباحثان بالآتى: عددود من مكاتب المحاسبة }
$$

- - ضرورة اهتمام مكاتب المحاسبة فى مصر بتدريب مراقبى الحسابات على استخدام أدوات تكنولوجيا المعلومات وخاصة فيما يتعلق بمراجعة سلسلة الكتل.

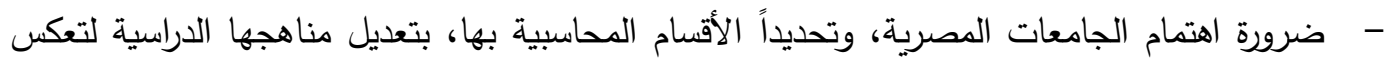
الاهتمام العام على مستوى الدولة بموضوع ريادة الأعمال بصفة عامة وريادة الأعمال المهنية المحاسبية على وجه الخصوص. - - - ضرورة اهتمام هيئة الرقابة المالية، وإدارة البورصة والاتحاد العام للغرف التجارية بعقد ندوات لتوعية أصحاب المصالح فى مصر بالدور الرائد الذى تلعبه مهنة المحاسبة فى إضفاء الثقة على القوائم المالية، مما يساعد متخذى القرارات المختلفين فى اتخاذ قراراتهم. 
- - يجب الإسراع بإنثاء المجلس الأعلى للمحاسبة كتنظيم مهنى مناظر للتظيمات المهنية العالمية يضطلع بمهامه ويعمل على الحد من تركز خدمات المراجعة والفحص المحدود والخدمات الأخرى لإسى بخلاف المراجعة فى عدد محدود من مكاتب المحاسبة، ومن ثم دعم المنافسة المهنية. - تثجيع رواد الأعمال فى مجال المحاسبة على دخول مهنة المحاسبة والمنافسة العادلة بين مكاتب لـن المحاسبة المختلفة. - يجب أن تهتم أقسام المحاسبة بالجامعات الحكومية بعقد مؤتمرات علمية محاسبية تخصصية فى مجال

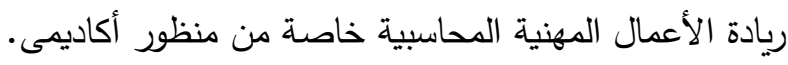

\section{وبناء عليه، اقترح الباحثان مجالات بحث مستقبلية، أهمها ما يلى:}

- - دراسة مقارنة لمدى استيفاء مراقبى الحسابات فى مصر وبعض الدول العربية لمؤشر متطلبات ريادة الأعمال المهنية المحاسبية.

- مدى استيفاء المحاسبين بالشركات لمؤشر منطلبات ريادة الأعمال المهنية المحاسبية: دراسة

$$
\text { ميدانية. }
$$

- - أثر إفصاح مكاتب المحاسبة فى مصر ، ضمن تقارير الشفافية المهنية، عن التزامها بمتطلبات ريادة الأعمال المهنية المحاسبية على جودة التقارير المالية لعملائها.

\section{قائمة المراجع}

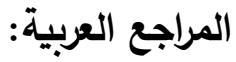

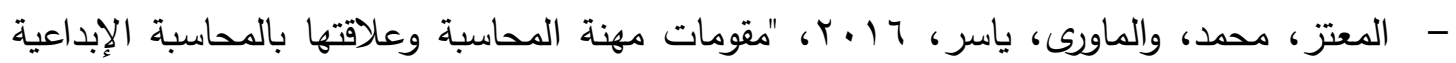
فى الدول العربية - دراسة استطلاعية على المهنيين والأكاديميين فى اليمن"، مجلة الأندلس للعلوم

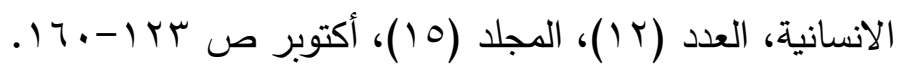

- رمو، وحيد واسماعيل، بشير، V V. Y، "الارتقاء بالتدريب المهنى ودوره فى تعزيز التقة بمهنة المحاسبة - دراسة استطلاعية فى اقليم كردستان - العراق"، مجلة كلية التراث الجامعة - العدد

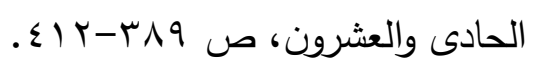

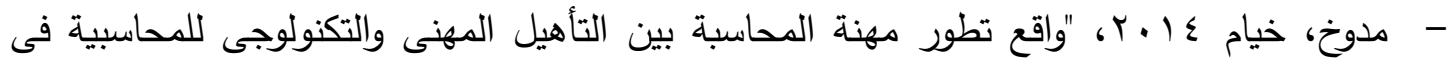
الثركات العاملة فى قطاع غزة"، رسالة ماجستير - قسم المحاسبة والتمويل بكلية التجارة -

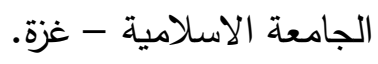




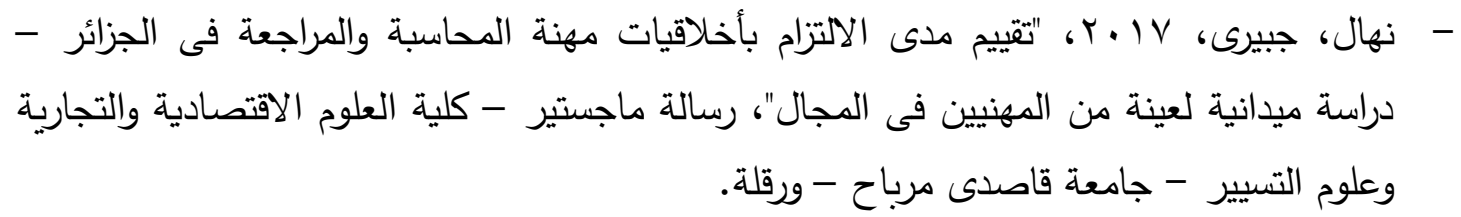

\section{English References:}

$$
\text { وعلوم التسيير - جامعة قاصدى مرباح - ورقلة. }
$$

- Ahmad, I., \& Abdel-Aziz, M., 2015, “Assessing Entrepreneurship Ecosystem in Egypt: Access to Finance and Entrepreneurship Education Challenges and Opportunities", available at: https://www.researchgate.net/publication/308548313

- Ahmad, N., \& Hoffman, A., 2007, "A Framework for Addressing and Measuring Entrepreneurship", OECD.

- Barth, M., 2018, "Accounting in 2036: A Learned Profession - Part 1: The Role of Research", The Accounting Review, Vol. 93, No. 6, pp. 383-385.

- Bloch, J., Brewer, P., \& Stout, D., 2012, "Responding to the Leadership Needs of the Accounting Profession: A Module for Developing a Leadership Mindset in Accounting Students", Issues in Accounting Education, Vol. 27, No. 2, pp. 525-554.

- Dal Mas, L., \& Barac, K., 2018, "The Influence of the Chief Audit Executive's Leadership Style on Factors Related to Internal Audit Effectiveness", Managerial Auditing Journal, Vol. 33, No. 8/9, pp. 807835.

- DeCoster, J., 2004, "Data Analysis in SPSS", retrieved February, 5, 2020 from http://www.stat-help.com/notes.html.

- Desai, S., 2017, "Measuring Entrepreneurship: Type, Motivation, and Growth", IZA World of Labor, Vol. 327, pp. 1-10.

- European Commission, 2008, "Entrepreneurship in higher education, especially within non- business studies", available at: http://ec.europa.eu/enterprise/newsroom/cf/itemdetail.cfm?item_id=3366.

- Godin, K., Clemens, J., \& Veldhuis, N., 2008, "Measuring Entrepreneurship - Conceptual Frameworks and Empirical Indicators", Studies in Entrepreneurship Markets, No. 7, pp. 1-66.

- Huber, W., 2012, "Is Forensic Accounting in the United States Becoming a Profession", Journal of Forensic \& Investigative Accounting, Vol. 4, No. 1, pp. 255-284.

- Iversen, J, Jorgensen, R., \& Malchow-Moller, N., 2008, "Defining and Measuring Entrepreneurship", Foundations and Trends in Entrepreneurship, Vol. 4, No. 1, pp. 1-63.

- Kobia, \& Sikalieh, 2010, "Towards a Search for the Meaning of Entrepreneurship", Journal of European Industrial Training, Vol. 34, No. 2, pp. 110-127. 
- Law, P., \& Hung, J., 2009, "Factors Influencing Hong Kong CPA's Entrepreneurship in the Accounting Profession", Journal of Human Resource Costing \& Accounting, Vol. 13, No. 1, pp. 29-45.

- Lunati, M., 2010, "The OECD-Eurostate Entrepreneurship Indicators Programme", OECD, $4^{\text {th }}$ Meeting of the MENA-OECD WG2.

- Marcotte, C., 2013, "Measuring Entrepreneurship at the Country Level: A Review and Research Agenda", Entrepreneurship \& Regional Development: An International Journal, Vol. 25 (304), pp. 174-194.

- Mitter, C., \& Hiebl, M., 2017, "The Role of Management Accounting in International Entrepreneurship", Journal of Accounting \& Organizational Change, Vol. 13, No. 3, pp. 381-409.

- Murigi, E., 2016, "5 Reasons Accountants make Successful Entrepreneurs", Morgan International, accessed 17 January 2020, $<$ https://www.morganintl.com/blog/accounting-auditing/5-reasonsaccountants-make-successful-entrepreneurs>

- QAA, 2018, "Enterprise and Entrepreneurship Education: Guidance for UK Higher Education Providers",available at: www.qaa.ac.uk.

- Rayan, A., \& Aryasri, A., 1999, "Enterprising Tendency among Omani Graduates: An Empirical Study of a Selected Group", Journal of Commercial Research, Faculty of Commerce, Zagazeeg University, Vol. 21, No. 1, pp. 3-30.

- Schiopoiu, A., Mihai, M., \& Mihai, L., 2016, "The Leadership of the Accounting Students: A Dilemma for Higher Education", International Journal of Organizational Leadership, Vol. 5, pp. 299-306.

- Schoch, H., \& Teoh, H., 1995, "An Entrepreneurial Role for the Accountant: Innovation in the cost-Price Relationship and the Accounting Marketing Interface", Journal of Small Business and Entrepreneurship, Vol. 12, No. 4, pp. 3-18, Oct-Dec.

- Sellers, R., Fogarty, T., \& Parker, L., 2015, "The Center Cannot Hold: The AICPA and Accounting Professional Leadership 1997-2013", Accounting Horizons, Vol. 29, No. 3, pp. 485-506.

- Sharma, U., Lawrence, S., \& Lowe, A., 2014, "Accountants as Institutional Entrepreneurs: Changing Routines in a Telecommunications Company", Qualitative Research in Accounting \& Management, Vol. 11, No. 3, pp. 190-214.

- Sousa, M., \& Almeida, M., 2014, "Entrepreneurial Skills Development", Recent Advances in Applied Economics, available at: https://www.researchgate.net/publication/268816221

- United Nations, 2012, "Entrepreneurship Policy Framework and Implementation Guidance", United Nations Conference on Trade and Development, available at: http://unctad.org.

- Zimmerman, J., 2008, "Refining the Definition of Entrepreneurship", A dissertation submitted in partial satisfaction of the requirements for the 
degree of Doctor of Education in Organizational Leadership, Pepperdine University, Graduate School of Education and Psychology.

\section{ملحق الدراسة \\ استطلاع أى}

يقوم الباحثان بدراسة استطلاعية تستهدف الكثف عن آراء مراقبى الحسابات فى مجال ريادة Accounting بصفة عامة وريادة الأعمال المهنية المحاسبية الأعمال Business Entrepreneurship على وجه الخصوص. والباحثان إذ يقدران لكم مسبقاً حسن تعاونكم معهما، فبرجاء الرد على كافة الأسئلة المرفقة، علماً بأن ردودكم ستكون سرية وسوف تستخدم لأغراض البحث العلمى فقط. 


$$
\begin{aligned}
& \text { الباحثان }
\end{aligned}
$$

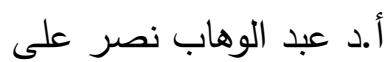

$$
\begin{aligned}
& \text { استاذ المحاسبة والمراجعة بكلية التجارة - جامعة الاسكندرية } \\
& \text { Email: abdelwahab.nasr@hotmail.com } \\
& \text { د. هبة الله عبد السلام بدوى } \\
& \text { استاذ المحاسبة والمراجعة المساعد بكلية التجارة - جامعة الاسكندرية } \\
& \text { والجامعة المصرية اليابانية للعلوم والتكنولوجيا }
\end{aligned}
$$

Email: heba.badawy@ejust.edu.eg

$$
\text { ولكم جزيل الثكر،،، }
$$

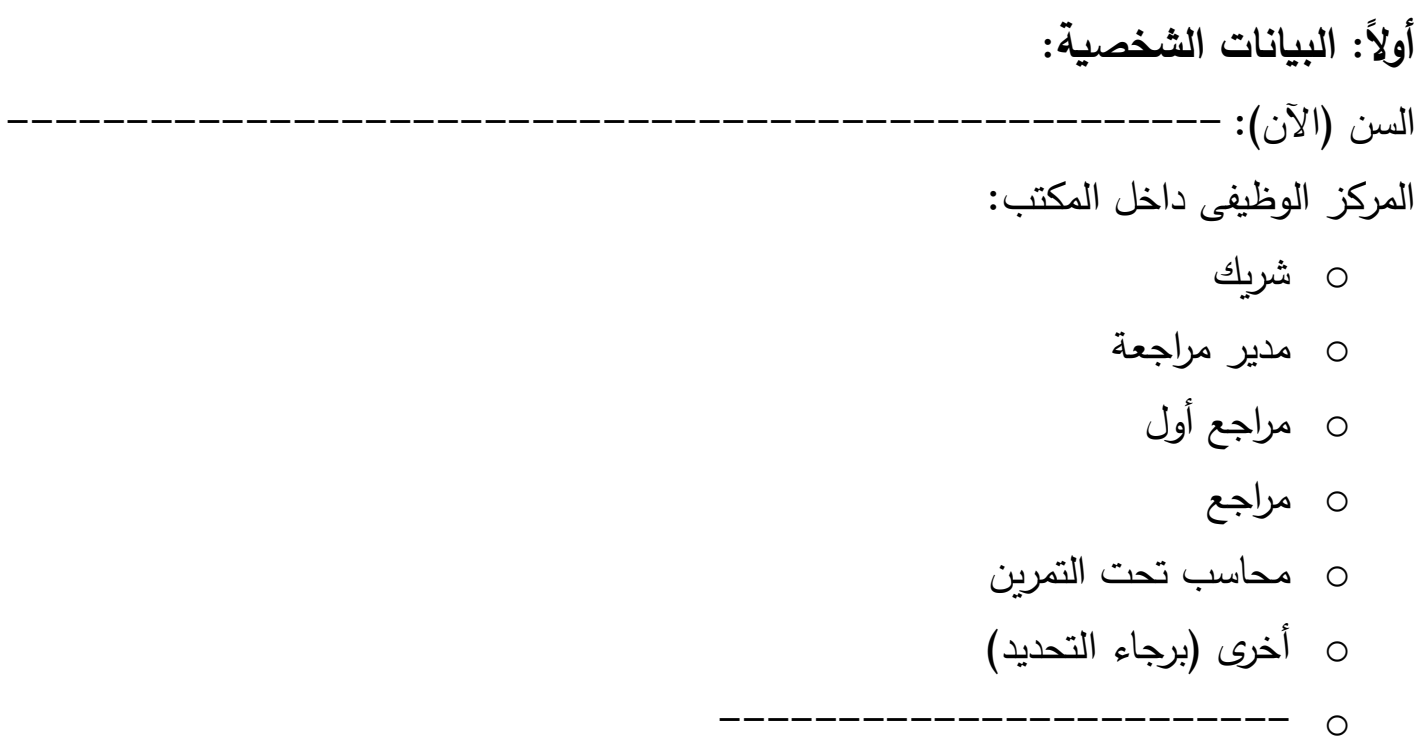




$$
\begin{array}{r}
0 \\
0 \\
0 \\
0 \\
0 \\
0 \\
0 \\
0 \\
0
\end{array}
$$

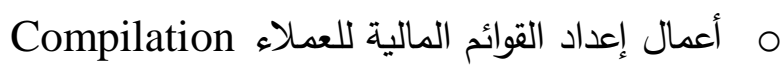

$$
\text { م أعمال مراجعة القوائم المالية السنوية ورقياً }
$$

C أعمال المراجعة المستمرة Continuous Auditing

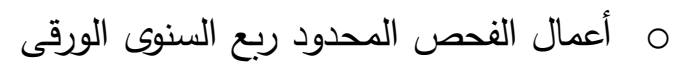

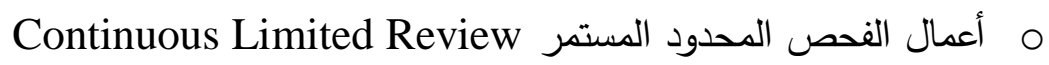
م أداء خدمات استثارية (اذكر أنواعها من فضلك)

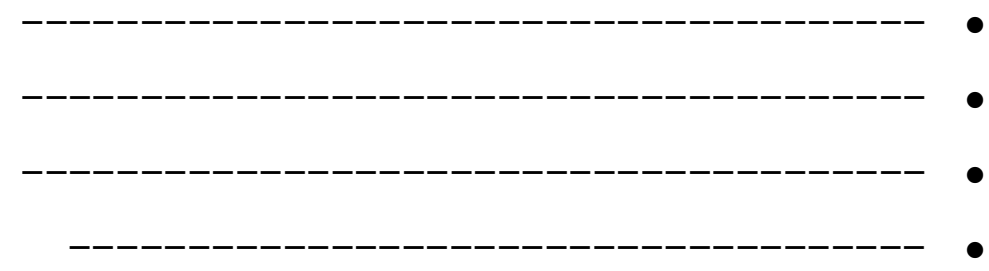

$$
\text { ○ أخرى (برجاء التحديد) }
$$
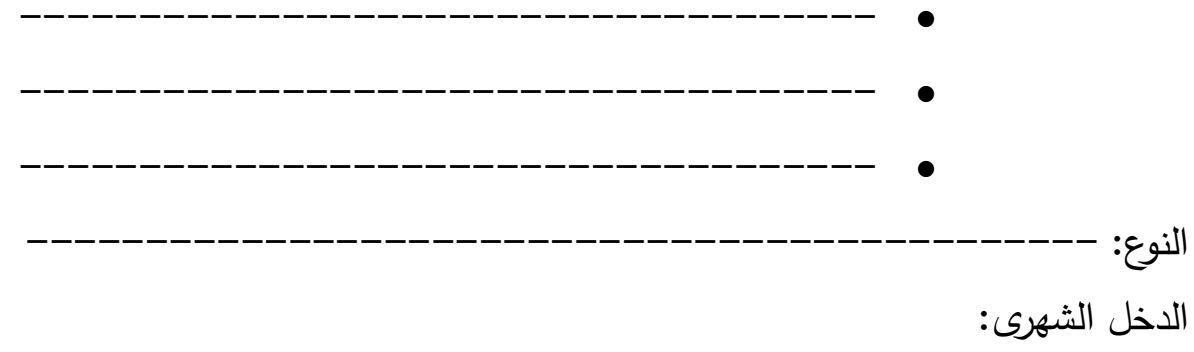

$$
\text { 0 } 0
$$




$$
\begin{aligned}
& \text { م من . ... } \\
& \text { ا أكثر من من .... } \\
& \text { المؤهل العلمى: }
\end{aligned}
$$

o بكالوريوس محاسبة: سنة

\begin{tabular}{|c|c|c|c|}
\hline ע & ن امم & & السؤال \\
\hline & & & 1 - الإطار التنظيمي \\
\hline & & $\mathrm{O} 1$ & هل يمكن للمحاسب تحت التمرين الآن التسجيل في السجل العام للمحاسبين بوزارة المالية بسهولة؟ \\
\hline & & $\mathrm{O} 2$ & السلوك يقوم مكتب المأسبة بتعريف القيم التي يجب أن يحافظ عليها أعضاؤه ويقوم بتطوير دستور \\
\hline & & $\mathrm{O} 3$ & هل يحدد مكتب المحاسبة دور إدارته فى الوفاء بتوقعات الجمهور تجاه الخدمات المهنية التي يقدمها؟ \\
\hline & & $\mathrm{O} 4$ & وخل يقوم مكتب المحاسبة بتهيئة جو من الشفافية يشجع أعضائه على مشاركة مشكلاتهم ومعرفتهم \\
\hline & & $\mathrm{O} 5$ & هل يتم تقسيم العمل بالمكتب بحسب الاختصاص والتتسيق بين المهام حتى يتم تحقيق أهداف المكتب بفاعلية؟ \\
\hline
\end{tabular}

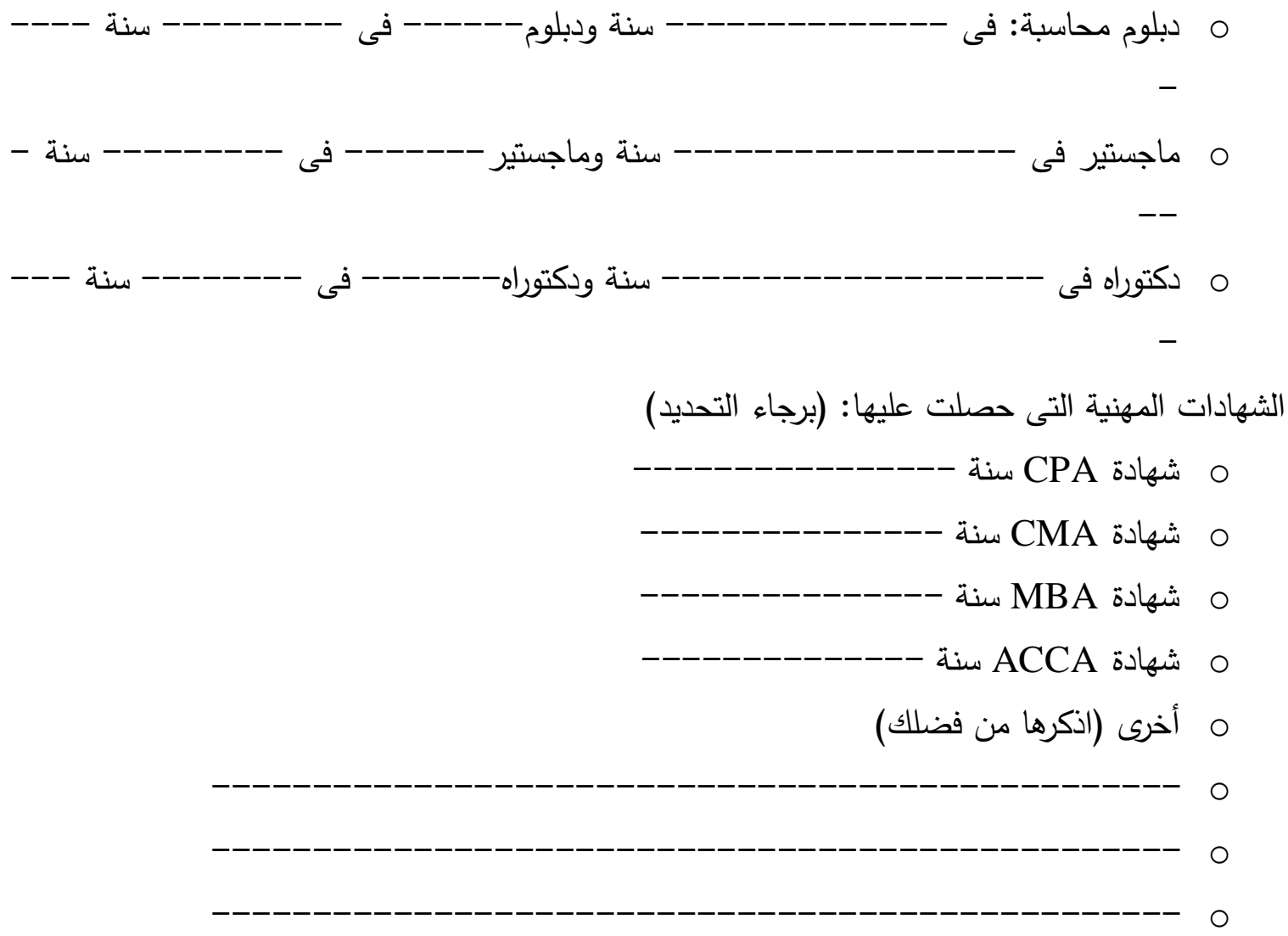

ثانياً: أسئلة الدراسة: 


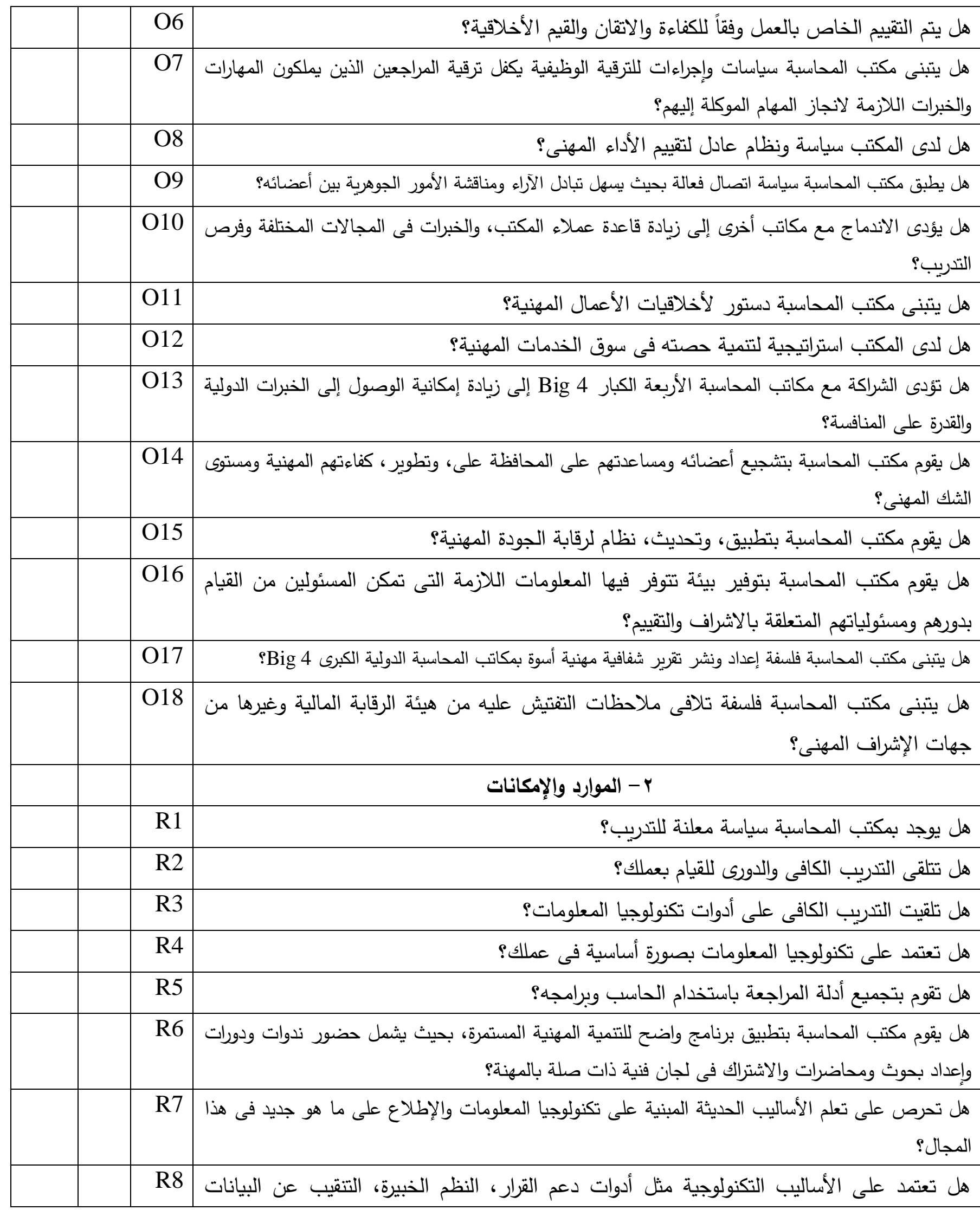




\begin{tabular}{|c|c|}
\hline & \\
\hline R9 & هل تستطيع استخدام أدوات المراجعة التى تعتمد على الحاسب بسهولة؟ \\
\hline R10 & هل تعتمد على تحليلات البيانات Data Analytics فى سياق إجراءات المراجعة وجمع الأدلة؟ \\
\hline R11 & هل تدربت على المراجعة فى حالة سلسلة الكتل Blockchain \\
\hline & 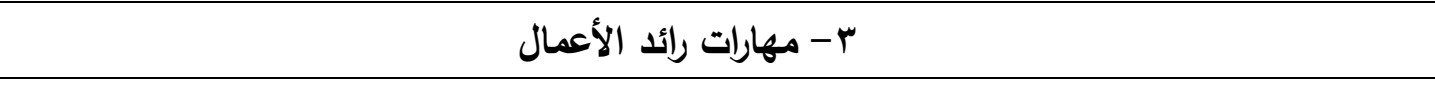 \\
\hline S1 & هل لديك خلفية عن ريادة الأعمال بصفة عامة؟ \\
\hline S2 & هل لديك خلفية عن ريادة الأعمال المهنية المحاسبية بصفة خاصة؟ \\
\hline S3 & هل تلقيت منهجا دراسيا عن ريادة الأعمال خلال فترة دراستك الجامعية؟ \\
\hline S4 & هل لديك رغبة لأن تصبح رائد أعمال مهنية محاسبية؟ \\
\hline S5 & هل أنت مقتتع بقضية ريادة الأعمال عامة والمهنية المحاسبية خاصة؟ \\
\hline S6 & هل توافق على أن لريادة الأعمال المهنية المحاسبية مردود مادى ومعنوى وتنافسى مهنى؟ \\
\hline S7 & هل أنت من المجازفين ومتحملى المخاطر؟ \\
\hline S8 & هل لديك ثقة فى نفسك على تحقيق أهدافك وتخطى الصعاب؟ \\
\hline S9 & هل تمتلك مهارات اتصال (كتابة وتحدث) مناسبة؟ \\
\hline S10 & هل تستمع إلى الآخرين؟ \\
\hline S11 & هل انت دقيق وغير متهاون فى المشاكل التى تقابلها سواء كانت صغيرة أو كبيرة؟ \\
\hline S12 & هل تقوم بإجراء تقييم ذاتى لأدائك بصفة دورية؟ \\
\hline S13 & هل تحرص على أن يكون للك شبكة علاقات مع الآخرين من داخل وخارج مكتب المحاسبة؟ \\
\hline S14 & هل انت مقتنع بمفهوم فريق العمل المهنى؟ \\
\hline S15 & 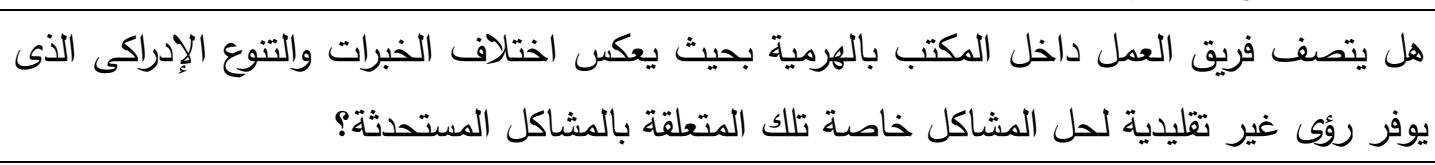 \\
\hline S16 & هل حددت لنفسك أهداف مهنية طويلة الأجل؟ \\
\hline S17 & هل تبذل أقصى ما فى وسعك لكى تكون من رواد الممارسة المهنية المحاسبية فى مصر مستقبلا؟ \\
\hline S18 & هل تخطط لكى تكون حصة مكتبكم بالسوق فى نمو مستمر؟ \\
\hline S19 & هل أنت حريص على أداء خدمات مهنية مستحدثة دوما لعملائك؟ \\
\hline S20 & هل تسعى دائماً على تطوير مهارات فريق العمل الذى ترأسه؟ \\
\hline S21 & هل أنت مقتنع بجلسات العصف الذهنى Brainstorming مع أعضاء فريق العمل؟ \\
\hline S22 & هل حضرت مؤتمرات فى ريادة الأعمال بصفة عامة؟ ـ \\
\hline & 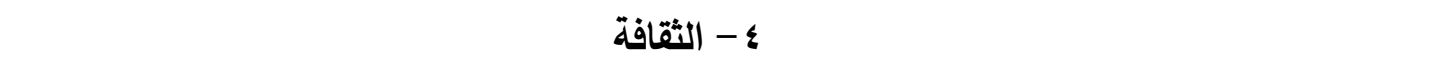 \\
\hline
\end{tabular}




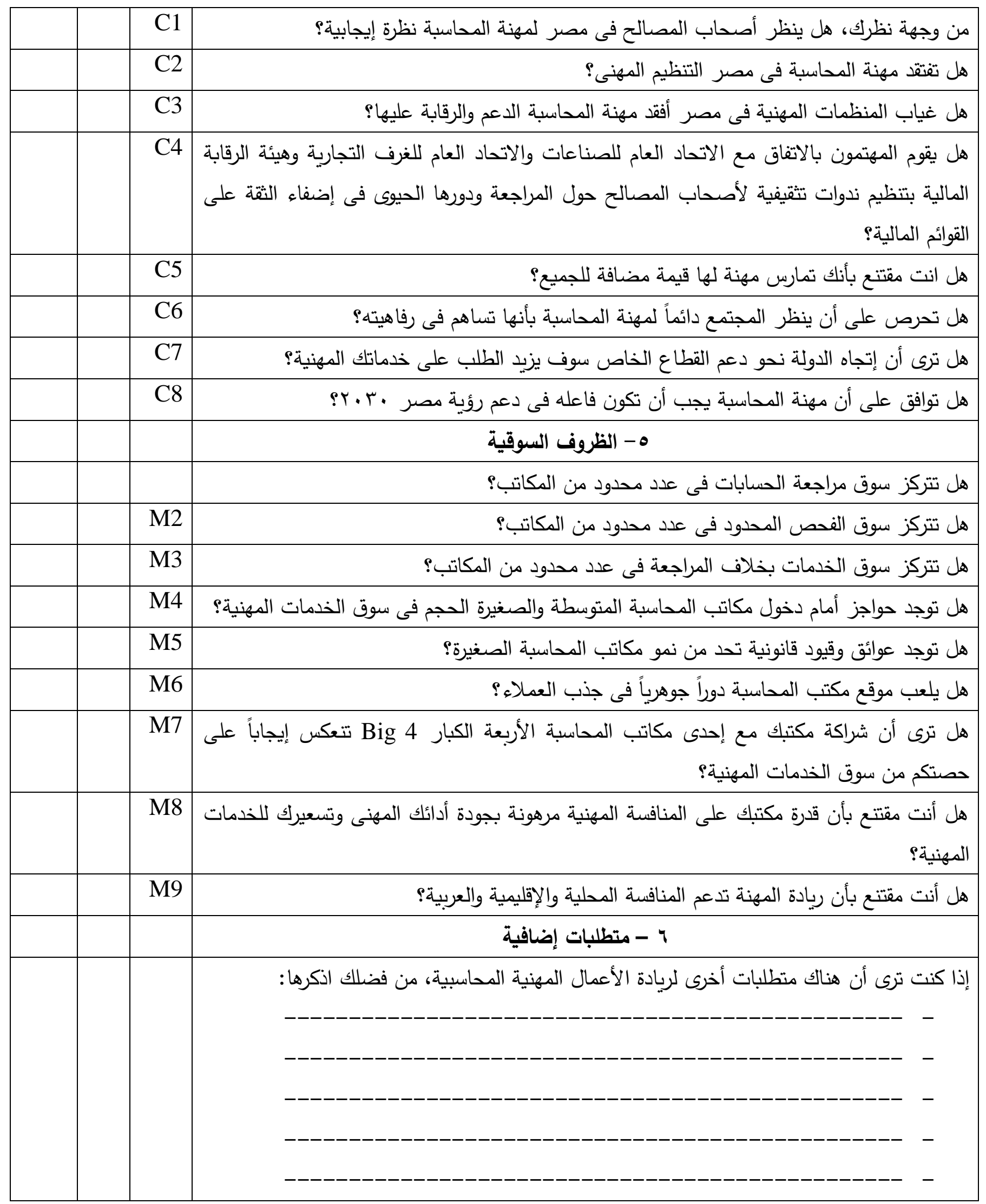


